Hans-Hilger Ropers, Julia Diekämper, Anja Hümpel

\title{
4. Themenbereich Gendiagnostik: Hochdurchsatz-Sequenzierung - eine Chance für die genetische Krankenversorgung in Deutschland
}

\subsection{Aktueller Stand}

Die Gendiagnostik hat den „Gentechnologiebericht“ von Beginn an beschäftigt. Neben der Diagnose genetisch bedingter Krankheiten, welche prädiktive und vorgeburtliche Tests sowie Reihenuntersuchungen einschließt, geht es dabei auch um die Erkennung bisher unbekannter Gendefekte, da die meisten dieser Störungen noch immer nicht aufgeklärt sind. Besonders in den letzten Jahren sind die Entwicklungen auf diesem Gebiet von weitreichenden technischen Neuerungen geprägt. Mit ihrer gegenwärtigen Bandbreite an Möglichkeiten hat die Gendiagnostik weiter an gesellschaftlicher Bedeutung und Brisanz gewonnen, was sich in einer Vielzahl gesellschaftspolitischer Diskussionen und Stellungnahmen zu diesem Thema niedergeschlagen hat. Nach dem Erscheinen des

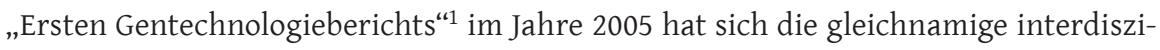
plinäre Arbeitsgruppe der Berlin-Brandenburgischen Akademie der Wissenschaften (BBAW) regelmäßig mit den Fortschritten auf dem Gebiet der Gendiagnostik befasst, so durch Veröffentlichung eines Supplements zur "Gendiagnostik in Deutschland“ (2007) ${ }^{2}$ und erneut im „Zweiten Gentechnologiebericht“ (2009)3. Gemeinsam mit der Nationalen Akademie der Wissenschaften Leopoldina und der Deutschen Akademie der Technikwissenschaften acatech veröffentlichte sie 2010 eine Stellungnahme „Prädiktive genetische Diagnostik als Instrument der Krankheitsprävention“. ${ }^{4}$ Unlängst schließlich erschien unter Schirmherrschaft der BBAW die Stellungnahme „Neue Sequenzierungstechniken und ihre Konsequenzen für die genetische Krankenversorgung“ (April 2013).

1 http://edoc.bbaw.de/volltexte/2007/375/ [27.06.2014].

2 http://edoc.bbaw.de/volltexte/2009/832/ [07.05.2014].

3 http://edoc.bbaw.de/volltexte/2010/1730/ [07.05.2014].

4 www.leopoldina.org/uploads/tx_leopublication/201011_natEmpf_praedikative-DE.pdf [06.05.2014]. 
Auch der Deutsche Ethikrat trat im April 2013 mit einer Stellungnahme zur „Zukunft der genetischen Diagnostik - von der Forschung in die klinische Anwendung“5 an die Öffentlichkeit, und im Juni desselben Jahres befasste sich das Marsilius-Kolleg der Universität Heidelberg mit „Eckpunkten für eine Heidelberger Praxis der Ganzgenomsequenzierung “6. Die hier genannten Veröffentlichungen stellen notwendigerweise nur einen Ausschnitt des öffentlichen Diskurses dar, der sich mit der Entwicklung der Gendiagnostik und den daran geknüpften Erwartungen kritisch auseinandersetzt. Ausgewählte Aspekte werden im Folgenden näher beleuchtet.

Der Vorschlag, die komplette menschliche Erbsubstanz mit ihren mehr als drei Milliarden DNA-Basen zu sequenzieren, stammt bereits aus den 1980er-Jahren. Die technischen Möglichkeiten dafür wurden erst ab 1990 im Laufe des Humangenomprojekts entwickelt, welches schließlich in der Sequenzierung des Humangenoms gipfelte (Landers et al., 2001; Venter et al., 2001). An das Erreichen dieses Meilensteins der modernen Genomforschung knüpfte sich eine Vielzahl von Hoffnungen für die biomedizinische Anwendung, vor allem auch in Bezug auf die Identifizierung genetischer Risikofaktoren für häufige „multifaktoriell“ bedingte Krankheiten, die auf ein Wechselspiel genetischer und nicht genetischer Faktoren zurückgeführt werden. Seit der routinemäßigen Verwendung hochauflösender DNA-Chips, welche die gleichzeitige Typisierung von vielen Hunderttausend genetischen Markern und die Untersuchung großer Stichproben erlauben, wurden in schneller Folge genetische Varianten gefunden, die bei Patienten mit bestimmten komplexen Krankheiten signifikant häufiger vorkommen als bei Gesunden. Indes zeigte sich schon bald, dass sich die allermeisten dieser krankheitsassoziierten Varianten nicht als diagnostische oder prognostische Marker eignen, da ihr Vorhandensein oder Fehlen das Erkrankungsrisiko nur geringfügig modifiziert. Auch für das Verständnis der molekularen Pathogenese häufiger Krankheiten hat die Suche nach assoziierten genetischen Markern bisher nur in wenigen Fällen grundlegend neue Erkenntnisse erbracht. Daher hat sich die Genomforschung in jüngerer Zeit wieder verstärkt den monogenen Krankheiten zugewandt (vgl. etwa Check Hayden, 2009; Ropers, 2010). Darunter versteht man Störungen, die auf Defekte einzelner Gene zurückgehen. Die Aufklärung derartiger Gendefekte eröffnet - im Unterschied zu den allermeisten krankheitsassoziierten Markern - in vielen Fällen direkte Einblicke in die relevanten pathogenen Mechanismen und therapeutischen Möglichkeiten.

5 www.ethikrat.org/dateien/pdf/stellungnahme-zukunft-der-genetischen-diagnostik.pdf [06.05.2014].

6 www.marsilius-kolleg.uni-heidelberg.de/md/einrichtungen/mk/presse/mk_eurat_stellungnahme_2013.pdf [10.07.2014] 
Ein anderer Schwerpunkt früherer Stellungnahmen war die Entwicklung und Einführung der Microarray-basierten komparativen genomischen Hybridisierung (Array-CGH). Im Unterschied zur konventionellen Chromosomenanalyse ermöglicht die Array-CGH die Erkennung von submikroskopisch kleinen unbalancierten Chromosomenveränderungen. Mithilfe dieser Methode gelang es, eine Vielzahl früher unbekannter Mikrodeletionen und Duplikationen als Ursache von psychomotorischen Störungen, Fehlbildungen und anderen Krankheiten zu identifizieren. Im Bereich der genetischen Diagnostik hat die Array-CGH-Analyse in einigen Ländern - wie den USA und den Niederlanden - die konventionelle Chromosomenanalyse inzwischen weitgehend verdrängt. Auch in Deutschland wurde diese Methode im Jahre 2013 mit einer eigenen EBM-Ziffer ${ }^{7}$ (11500) in den Leistungskatalog der gesetzlichen Krankenversicherung aufgenommen und ist seither abrechnungsfähig. Voraussetzung dafür war die klinische Validierung der Array-CGH im Rahmen einer vom Bildungsministerium für Bildung und Forschung (BMBF) finanzierten vernetzten Studie unter Beteiligung großer forschungsaktiver universitärer Einrichtungen in Deutschland, wie vorher vom „Gentechnologiebericht“ empfohlen (Ropers/Ullmann, 2007:22 ff.).

Seit 2007 gewannen neue Methoden zur Hochdurchsatz-DNA-Sequenzierung für die Genomforschung und die genetische Krankenversorgung zunehmend an Bedeutung. Fortschritte wurden vor allem bei der Aufklärung monogener Krankheiten erzielt. Überdies konnte gezeigt werden, dass bei vielen häufig „multifaktoriell bedingten“ Krankheiten Defekte einzelner Gene ebenfalls eine bedeutende Rolle spielen. Aufgrund der raschen Fortschritte auf diesem Sektor, aber auch der unterschiedlichen Struktur relevanter Datenbanken ist es jedoch schwierig, verbindliche Aussagen zur Zahl der bis heute aufgeklärten Gendefekte zu machen, die mit monogenen Krankheiten assoziiert sind. Die Angaben dazu variieren zwischen $3.112^{8}$ und $4.364^{9}$ Krankheitsgenen. Ein amerikanisches Konsortium spricht sogar von 4.600 bekannten Genen, die zusammen das „Medical Genome“ ausmachen sollen, jedoch ohne überprüfbare Details (Heger, 2014). Die Anzahl molekular aufgeklärter monogener Krankheiten hat sich demnach seit der Publikation des „Zweiten Gentechnologieberichts“ im Jahre 2009 mehr als verdoppelt. Dennoch dürfte die große Mehrzahl aller krankheitsverursachenden Gendefekte noch immer unbekannt sein. Vieles deutet darauf hin, dass Defekte von mindestens der Hälfte, vielleicht sogar drei Viertel aller 20.000 menschlichen Gene (Cooper et al., 2010) zu monogenen Krankheiten führen können. Dafür spricht auch der mit circa

$7 \quad \mathrm{EBM}=$ Einheitlicher Bewertungsmaßstab.

8 http://orphadata.org/cgi-bin/index.php/ [05.04.14].

9 Human Gene Mutation Database, release 2013.3; (Hao Hu, Januar 2014, pers. Mitteilung an H. H. Ropers). 
30 Prozent noch immer geringe Anteil aller Patienten mit genetisch bedingten Krankheiten, die sich durch Mutationen in proteinkodierenden Abschnitten bereits bekannter Krankheitsgene erklären lassen (Iglesias et al., 2014). Zum Teil dürfte diese geringe Ausbeute jedoch methodische Gründe haben, da die Anzahl identifizierter Mutationen bei der Sequenzierung des gesamten Genoms (Whole Genome Sequencing, WGS) anscheinend wesentlich höher ist als bei der Sequenzierung angereicherter kodierender Genomabschnitte (Whole Exome Sequencing, WES) (Gilissen et al., 2014). Für die WGS als diagnostisches Verfahren (und tendenziell gegen die Sequenzierung von Panels ausgewählter Gene) spricht auch die Beobachtung, dass Defekte spezifischer Gene zu ganz unterschiedlichen Krankheitsbildern führen können (Beaulieu et al., 2014), wie unten ausgeführt.

Mithilfe der WGS (und mit Einschränkungen auch durch WES) lassen sich die meisten krankheitsverursachenden Gendefekte erfassen, auch solche, die zum ersten Mal beobachtet werden. Eindeutig diagnostizieren kann man sie allerdings erst, wenn man bei mehreren Patienten mit dem gleichen Krankheitsbild Defekte desselben Gens gefunden oder (z. B. durch funktionelle Untersuchungen an Tiermodellen) gezeigt hat, dass Defekte dieses Gens für diese Krankheit ursächlich verantwortlich sind.

Somit hängt der Fortschritt bei der Identifikation neuer Krankheitsgene maßgeblich von der Anzahl sequenzierter Genome Erkrankter ab, da sich auf diesem Wege viel rascher als durch funktionelle Untersuchungen ein eindeutiger Bezug zwischen spezifischen Krankheitsbildern und Gendefekten herstellen lässt. Angesichts der Vielzahl noch unbekannter Gendefekte und ihrer klinischen Variabilität sprengt die Suche nach Patienten mit klinisch und molekular ähnlich gelagerten Befunden jedoch den Rahmen selbst großer Modellstudien. Schnelle Fortschritte bei der Aufklärung bisher unbekannter Gendefekte lassen sich daher nur von der Implementierung der Genomsequenzierung im Rahmen der genetischen Diagnostik erwarten, wie bereits in der obengenannten BBAW-Stellungnahme vom April 2013 ausgeführt.

Für die Organisation und die Praxis der genetischen Diagnostik in Deutschland kommen diese Entwicklungen einem radikalen Umbruch gleich. Darum geht es im folgenden Beitrag, der sich auf die technischen und praktischen Grundbedingungen, den wissenschaftspolitischen Rahmen und den absehbaren Handlungsbedarf fokussiert. Für die Krebsforschung und -diagnostik sind diese Entwicklungen ebenfalls von zentraler Bedeutung. Jedoch sind erworbene somatische Genomveränderungen nicht Gegenstand dieser Stellungnahme, und sie werden daher nur am Rande erwähnt. 


\subsection{Technische Perspektiven}

Das Potenzial der Hochdurchsatzverfahren zur DNA-Sequenzierung zeichnete sich bereits bei der Veröffentlichung des „Ersten Gentechnologieberichts“ (2005) ab. Der „Zweite Gentechnologiebericht“ (2009) bilanzierte die rasche technische Weiterentwicklung der neuen Sequenzierungstechnologien, die seit 2006/2007 zu einer drastischen Kostenreduktion geführt und die Suche nach krankheitsrelevanten Mutationen im menschlichen Genom auf eine neue Basis gestellt haben. Sie waren bereits zu dem damaligen Zeitpunkt im Begriff, Eingang in die biowissenschaftliche Forschung zu finden. Der „Dritte Gentechnologiebericht“ schließlich befasst sich primär mit der Einführung der Hochdurchsatzsequenzierung (HDS) in die genetische Diagnostik und Krankenversorgung, die weltweit in vollem Gang ist. Im Folgenden sollen exemplarisch die aktuellen technischen Entwicklungen im Bereich der Ganzgenomsequenzierung und ihre Bedeutung für die (zukünftige) Krankenversorgung beleuchtet werden.

\subsubsection{Von der Hochdurchsatz-Sequenzierung zur Höchstdurchsatz- Sequenzierung}

Die Hochdurchsatz-Sequenzierung (HDS) hat die konventionelle (Sanger-)Sequenzierung $^{10}$ inzwischen in vielen Bereichen ersetzt, so geschehen in der Genomforschung und zunehmend auch in der genetischen Diagnostik. Die Sequenzierung nach Sanger wird häufig auch als Methode der ersten Generation bezeichnet und die Hochdurchsatzsequenzierung entsprechend als nächste (oder besser: zweite) Generation („next generation sequencing“, NGS). Hinter diesem Begriff verbirgt sich ein mittlerweile breites Spektrum verschiedener Verfahren, denen dennoch das gleiche Prinzip zugrunde liegt: Die zu sequenzierende DNA wird zunächst fragmentiert, die dabei entstehenden DNA-Fragmente werden anschließend enzymatisch vervielfältigt, und in einem dritten Schritt wird die Abfolge ihrer Basen (A, T, C, G) detektiert, wobei unterschiedliche Verfahren zum Einsatz kommen.

Der im Vergleich zur Sanger-Sequenzierung sehr hohe Probendurchsatz beruht vor allem darauf, dass Tausende bis Millionen von DNA-Fragmenten gleichzeitig sequenziert werden. Der weltweit erste Hochdurchsatz-Sequenzierer konnte pro Lauf bereits

10 Die konventionelle Sequenzierung von DNA-Molekülen (nach der sog. Kettenabbruchmethode) wurde bereits in den 70erJahren entwickelt (Sanger et al., 1977) und war vor der Einführung der HDSTechniken der „Goldstandard“. Auch wenn die Methode über die Jahrzehnte beständig weiterentwickelt und weitestgehend automatisiert wurde, ist sie im Vergleich zu den neueren HDS-Techniken arbeits- und zeitintensiver. Vgl. weiterführend zur historischen Entwicklung der DNASequenzierung etwa Hutchinson, 2007. 
circa 20 Millionen DNA-Basen $(20 \times 106$ bp) auslesen, was eine 100-fache Steigerung der Sequenzierleistung gegenüber der Sanger-Technologie darstellt. ${ }^{11}$ Indessen verlangten selbst kleine bakterielle Genome mehrere Durchgänge, um eine ausreichende Sequenzierungstiefe ${ }^{12}$ zu gewährleisten. In den Folgejahren drängten nicht nur weitere Anbieter auf den Markt, sondern die Leistungsfähigkeit der Geräte nahm stetig zu.

Wie im „Zweiten Gentechnologiebericht“ (Müller-Röber et al., 2009:117 ff.) angedeutet, war das Entwicklungspotenzial der zum damaligen Zeitpunkt vertriebenen NGS-Plattformen ${ }^{13}$ bei weitem noch nicht ausgereizt. Bei gleichzeitiger Diversifizierung des Angebots ${ }^{14}$ hat sich die Leistungsfähigkeit dieser Geräte seither in rasantem Tempo weiterentwickelt. Die Sequenzierplattform HiSeq X, die Anfang 2014 vom aktuellen Markführer Illumina, Inc. (USA) speziell für die Sequenzierung gesamter menschlicher Genome auf den Markt gebracht wurde (s. u.), verspricht bis zu 1,8 Billionen ausgelesene DNA-Basen (1,8 × 1012 bp) pro Gerät und Lauf. ${ }^{15}$ Theoretisch ist es möglich, mithilfe des HiSeq X Ten-Systems, einem Verbund aus zehn HiSeq X-Geräten, im Laufe eines Jahres bis zu 18.000 Genome mit einer 30-fachen Redundanz zu sequenzieren, die man für eine mehr oder weniger vollständige Abdeckung des Genoms benötigt.

Zeitgleich haben auch früher bereits vorgestellte Sequenzierungsverfahren der „übernächsten“ Generation ${ }^{16}$ (vgl. „Zweiter Gentechnologiebericht“, Müller-Röber et al., 2009:118), die einzelne DNA-Moleküle direkt, das heißt ohne vorherige klonale Amplifikation sequenzieren, Marktreife erlangt. ${ }^{17}$ Parallel dazu wurden für die klinische Diagnostik verschiedene kostengünstige Tischgeräte entwickelt. ${ }^{18}$ Diese Sequenziersysteme eignen sich aufgrund ihrer begrenzten Kapazität primär für die gleichzeitige Sequenzierung einiger 100 bis 1.000 Gene oder der proteinkodierenden Anteile des menschlichen Genoms, jedoch (noch) nicht für die Analyse des gesamten Humangenoms.

Ein technischer Durchbruch wird aktuell insbesondere auf dem Gebiet der Nanoporen-Sequenzierung erwartet, der bereits vor Jahren angekündigt wurde, jedoch bis

11 GS 20 (454 Life Sciences/Roche). Vgl. Margulies et al., 2005, Rothberg/Leamon, 2008.

12 Die Sequenzierungstiefe (engl. „sequencing depth“) beschreibt, wie häufig bei einer Sequenzierung ein bestimmter Genabschnitt ausgelesen wird, die Qualität steigt entsprechend mit der Häufigkeit.

13454 Genome Sequencer (Roche), Genome Analyzer (Illumina) und SOLiD (Applied Biosystems).

14 Ion Torrent Proton (Thermo Fisher Scientific).

15 http://res.illumina.com/documents/products/datasheets/datasheet-hiseq-x-ten.pdf[23.06.2014].

16 Auch als „dritte Generation“ bezeichnet, vgl. etwa Schadt et al., 2010, Thompson/Milos, 2011.

17 PacBio RS (Pacific Biosciences).

18 MiSeq (Illumina), Ion Torrent PGM (Thermo Fisher Scientific), 454 GS Junior (Roche). Vgl. etwa z. B. Loman et al., 2012, Für 2014 angekündigt: GeneReader (QIAGEN) 
heute ebenso ausgeblieben ist ${ }^{19}$ wie die Markteinführung eines auf dem Ion-TorrentPrinzip basierenden Sequenziersystems mit größerer Kapazität, das die Sequenzanalyse vollständiger menschlicher Genome erlaubt. Der andauernde Verdrängungswettbewerb der verschiedenen Anbieter (s. u.) und ein fehlendender Standard erschweren es, aktuelle und konsistente Aussagen über die unterschiedlichen HDS-Plattformen zu machen. ${ }^{20}$

\subsubsection{Hochdurchsatz-Sequenzierung in der klinischen Diagnostik}

HDS-Anwendungen im medizinisch-diagnostischen Bereich lassen sich vereinfacht in drei unterschiedliche Typen ${ }^{21}$ untergliedern: i) Diagnostik-Panels umfassen Gene, in denen Mutationen für eine Krankheit oder Krankheitsgruppe bekannt sind. Die Anzahl dieser gleichzeitig sequenzierten Gene kann stark variieren, von weniger als einem Dutzend bis zu mehreren Tausend Genen pro Panel. ${ }^{22}$ Die aufgrund des geringen Probenumfangs mögliche hohe Sequenzierungstiefe spricht für Panelsequenzierungen, jedoch beschränkt sich diese Analyse ausschließlich auf Mutationen in bereits bekannten Krankheitsgenen. ii) Beim Whole Exome Sequencing (WES) werden hingegen alle circa 20.000 menschlichen Gene erfasst und so auch bis dato unbekannte Mutationen identifizierbar. In einem ersten Schritt werden alle die in mRNA translatierten Abschnitte der Gene (= Exons, insgesamt: Exom) angereichert, einschließlich der Bereiche, die für Proteine codieren, und dann in ihrer Gesamtheit sequenziert. Allerdings liegen nicht alle krankheitsverursachenden Sequenzvarianten in exonischen Abschnitten (vgl. Lynch, 2010). iii) Am umfassendsten - aber bis vor Kurzem auch am kostspieligsten - ist daher die Ganzgenomsequenzierung oder Whole Genome Sequencing (WGS), die über das Exom hinaus auch alle nicht translatierten Genabschnitte (= Introns) und genregulierende Sequenzen erfasst. Die anhaltende Optimierung und Miniaturisierung der verschiedenen Hochdurchsatz-Sequenzierplattformen hat - neben den technischen Verbesserungen - aber auch eine drastische Kostenreduzierung nach sich gezogen. Entsprechend sind die Kosten für die Sequenzierung menschlicher Genome gefallen.

19 Das MinION (Oxford Nanopore Technologies) ist seit 2014 für ausgewählte Forschungsgruppen zugänglich (MinION Access Programme (https://www.nanoporetech.com/technology/the-miniondevice-a-miniaturised-sensing-system/minion-access-programme [25.06.2014]).

20 Es sei an dieser Stelle auf die Fülle an Fachartikeln bezüglich methodischer und technischer Besonderheiten der unterschiedlichen Sequenziersysteme verwiesen sowie auf die Websites der kommerziellen Anbieter.

21 Weiterführend: Ropers, 2012a.

22 Vgl. etwa http://www.cegat.de/Panel-diagnostik_22.html [17.06.2014] oder http://www.illumina. $\mathrm{com} /$ products/trusight-one-sequencing-panelilimn[17.06.2014]. 


\subsubsection{Das 1.000-Dollar-Genom}

Die Kosten für die Sequenzierung eines menschlichen Genoms sanken laut Angaben des US-amerikanischen National Human Genome Research Institute NHGRI (Abbildung 1) von mehr als 95 Millionen US-Dollar im Jahre 2001 auf rund sieben Millionen US-Dollar beim Erscheinen des Supplements „Gendiagnostik in Deutschland“ (Schmidtke et al. 2007). Bei Veröffentlichung des „Zweiten Gentechnologieberichts“ zwei Jahre später waren sie erneut um zwei Größenordnungen gefallen, und bis 2012 sanken sie auf weniger als 7.000 US-Dollar. Anfang 2014 näherten sich die Nettokosten für die Genomsequenzierung erstmalig der 1.000-Dollar-Grenze, ohne diese bisher zu unterschreiten.

Diese Kostensenkungen waren unter anderem eine Folge der Konkurrenz zwischen dem weltgrößten Hersteller von Hochdurchsatz-Sequenziersystemen (Illumina, Inc., USA) und dem bis dahin führenden kommerziellen Anbieter auf dem Gebiet der Genomsequenzierung (Complete Genomics, USA, mit eigenem, nicht kommerziell vertriebenem Sequenziersystem). Andere etablierte Hersteller von Hochdurchsatz-Sequenziersystemen haben in den letzten Jahren gegenüber Illumina Marktanteile verloren oder sind ganz vom Markt verschwunden. ${ }^{23}$

Im März 2013 kam es zur Übernahme der (zu dem Zeitpunkt wirtschaftlich defizitären) Firma Complete Genomics durch das chinesische Beijing Genomics Institute (BGI) in Shenzhen. ${ }^{24}$ Dadurch wurde das BGI von westlichen Herstellern von Sequenziersystemen unabhängig, und die Übernahme verschaffte Complete Genomics die finanziellen Mittel, um den Durchsatz ihres Sequenziersystems durch Mikrominiaturisierung massiv zu steigern und gleichzeitig die Kosten für die Genomsequenzierung zu senken (R. Drmanac, Oktober 2013, pers. Mitteilung an H. H. Ropers). Aufgrund der sich verschärfenden Konkurrenz trat Illumina Anfang 2014 mit der Mitteilung an die Öffentlichkeit, es werde in den kommenden Wochen ein neues System ausschließlich für die Sequenzierung von Humangenomen auf den Markt bringen, welches auf den Bedarf nationaler Genomzentren oder entsprechend großer diagnostischer Einrichtungen ausgelegt sei und bei vollständiger Auslastung eine Reduktion der Kosten auf weniger als 1.000 US-Dollar pro Humangenom möglich mache. ${ }^{25}$ Mittlerweile wurde das so annoncierte HiSeq X Ten-System an verschiedene große Genforschungszentren und Gendiagnostik-Institute ausgeliefert. (s. o.). Auch das BGI bietet heute die Genom-

23 Helicos Biosciences (USA) meldete 2012 Insolvenz an.

24 Vgl. www.completegenomics.com/news-events/press-releases/BGI-Shenzhen-Completes-Acquisition-of-Complete-Genomics-198854331.html [11.06.2014].

25 http://investor.illumina.com/phoenix.zhtml?c=121127\&p=irol-newsArticle\&ID=1890696 [24.06.2014]. 
sequenzierung für 1.000 US-Dollar an (J. Veltman, Nijmegen, Februar 2014, pers. Mitteilung an H. H. Ropers).

Abbildung 1: Kostenentwicklung der Genomsequenzierung

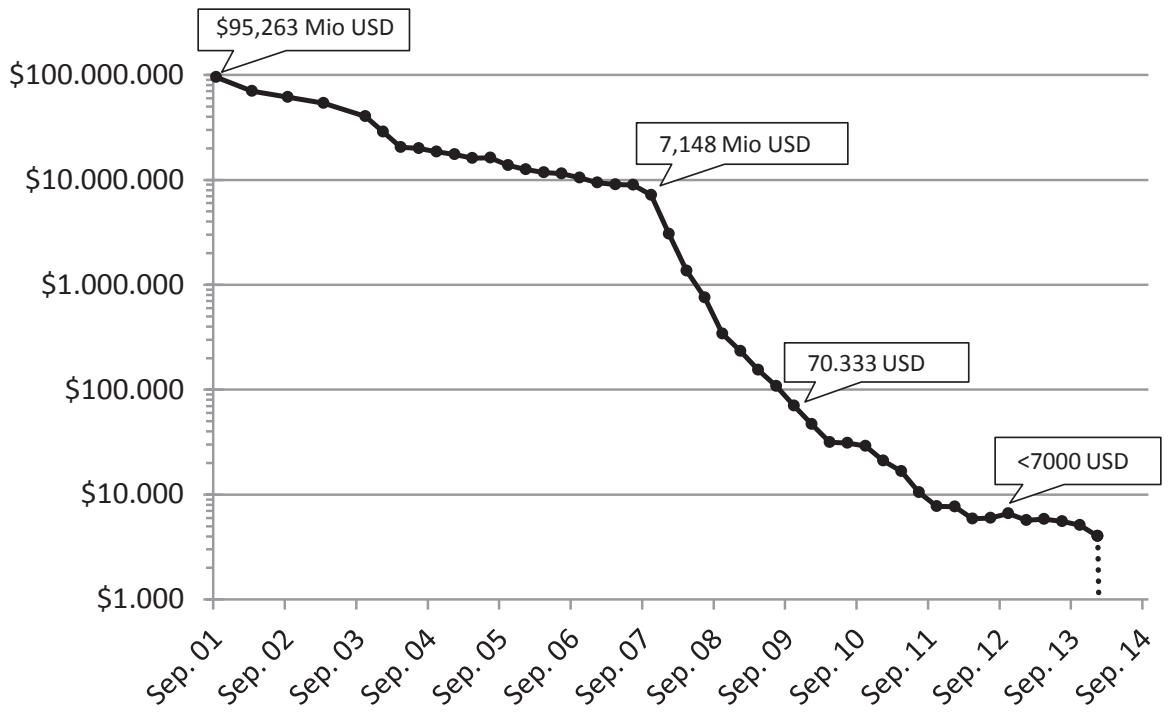

Kosten (USD) pro Humangenom. Quelle: NHGRI Genome Sequencing Program (GSP) unter http://www.genome. gov/27541954 [21.05.2014], aktuellster Stand zum Recherchezeitpunkt: 4008,11 USD 01/2014. Gestrichelte Linie: Kostensenkung durch die Markteinführung des HiSeq X Ten-Systems.

Nach jahrelangen Diskussionen über das „1.000-Dollar-Genom“ und seine Konsequenzen für die Krankenversorgung ist mit diesen Entwicklungen eine psychologisch bedeutsame Marke erreicht worden, wenn auch bisher nur für diejenigen, die keine Bedenken haben, sich bei der Gewinnung primärer Sequenzdaten in Abhängigkeit vom BGI zu begeben ${ }^{26}$ oder die Wenigen, die in der Lage sind, das mit zehn Millionen US-Dollar sehr kostspielige Illumina-System selbst zu nutzen. ${ }^{27}$ Jüngsten Informationen zufolge plant Complete Genomics, die Tochterfirma von BGI, in allernächster Zeit ebenfalls den Vertrieb eines Höchstdurchsatz-Sequenziersystems für nationale Genom- oder

26 Das BGI hat die erklärte Absicht, auf der Grundlage dieser Daten die weltgrößte Datenbank für krankheitsrelevante Sequenzvarianten aufzubauen und diese kommerziell zu nutzen (Quelle: South China Morning Post vom 16.12.2013).

27 Es ist zu beachten, dass die Vollkosten der Analyse des gesamten menschlichen Genoms den Betrag von 1.000 US-Dollar übersteigen, weil darin die Kosten für die bioinformatische Analyse der DNASequenzen, die klinische Beurteilung der Daten und Overheadkosten noch nicht enthalten sind. 
Gendiagnostikzentren. Damit und mit der geplanten Inbetriebnahme einer Vielzahl bereits bestellter HiSeq X Ten-Systeme dürfte sich die weltweite Überkapazität auf dem Gebiet der Genomsequenzierung weiter verstärken. Aufgrund der zunehmenden Konkurrenz verschiedener Anbieter ist die Genomsequenzierung auf dem Wege, zu einer kommerziellen Dienstleistung zu werden. Für den Umgang mit diesen Sequenzdaten, deren Auswertung und klinische Interpretation gilt dieses jedoch keineswegs, wie unten ausgeführt.

Heute ist der Punkt erreicht, an dem die Netto-Kosten für die HochdurchsatzSequenzierung (HDS) vollständiger menschlicher Genome kaum noch höher sind als die Aufwendungen für den Ausschluss eines einzigen spezifischen Gendefekts mithilfe konventioneller Sequenzierungsverfahren. Damit sind jetzt die technischen und die finanziellen Voraussetzungen für die Einführung der Genomsequenzierung in die genetische Diagnostik erfüllt, welche weitreichende Verbesserungen für die Krankenversorgung verspricht und der Genomforschung und Pharmaindustrie neue Chancen eröffnen wird. Auch die Beschränkung auf die Sequenzierung proteincodierender Genomabschnitte (WES) gegenüber der Sequenzierung ganzer Genome (WGS) bietet keine finanziellen Vorteile mehr, und auf Dauer dürfte Letztere sogar die HDS-gestützte Analyse von Genpanels ersetzen.

\subsection{Anwendungsformen und klinischer Nutzen}

Gendiagnostische Untersuchungen werden seit den 1970er-Jahren vor allem für klinische Anwendungen genutzt. ${ }^{28}$ Sie umfassen dabei durchaus mehr als die direkte Sequenzierung von DNA: Genetische Erkrankungen können auch über Analyse von RNA, Chromosomen, Proteinen und - in einigen Fällen - auch über fehlende oder sich anhäufende Stoffwechselprodukte oder indirekt über gekoppelte oder assoziierte Marker nachgewiesen werden. Die Entwicklungen in den letzten Jahren wie auch die stetig länger werdende Liste bekannter pathogener Genmutationen haben den Fokus in der Gendiagnostik zunehmend auf die genetische Ebene (DNA/Chromosomen) verschoben, worauf bereits in den vorangegangenen Publikationen der Arbeitsgruppe eingegangen wurde.

28 Daneben werden genetische Daten auch für nicht-medizinische Zwecke erhoben, auf die hier nicht weiter eingegangen wird: in der Forschung, für Abstammungsgutachten zur Klärung von Verwandtschaftsverhältnissen, für die Analyse biologischer Proben und Prüfung der Identität unbekannter Personen in der Strafverfolgung sowie für Anwendungen im Rahmen des Infektionsschutzes und zur Qualitätssicherung in der Lebensmittelindustrie. 


\subsubsection{Anwendungsformen klinisch-genetischer Diagnostik}

Im Folgenden ist das gegenwärtige Anwendungsspektrum klinisch-genetischer Diagnostik kurz vorgestellt. Dies lässt sich allgemein in vier verschiedene Gruppen unterteilen (siehe Abbildung 2), die sich vorrangig in Zeitpunkt und Zielsetzung der Verfahren unterscheiden.

Abbildung 2: Klinisches Anwendungsspektrum genetischer Untersuchungen

\section{diagnostische Tests}

- Abklärung einer bereits bestehenden genetischen Erkrankung

- Krebsdiagnostik

- Pharmakogenetische Untersuchungen

prädiktive Tests

- Abklärung einer erst zukünftig auftretenden genetischen Erkrankung

- Genetische Familienberatung bei Kinderwunsch

vorgeburtliche Risikoabklärung

- Pränatale Diagnostik (PND)

- Präimplantationsdiagnostik (PID)

Reihenuntersuchung (Screenings)

- Systematische Früherkennung von genetischen Krankheiten für ausgewählte Bevölkerungsgruppen

Diagnostische Tests dienen der individuellen Abklärung einer bereits bestehenden, klinisch fassbaren genetischen Erkrankung. Wie bereits erwähnt, ist die genetische Basis (häufiger) komplexer Erkrankungen - zum Beispiel Diabetes oder Altersdemenz - bisher nur unzureichend verstanden (vgl. etwa Ropers, 2010; Zielinski et al., 2012; Zuk et al., 2012). Bei den (für sich genommen seltenen) monogenen Erkrankungen wird aktuell von mehr als 4.000 bekannten Krankheitsgenen ausgegangen. Jedoch gibt es Grund für die Annahme, dass Veränderungen in zwei Drittel aller 20.000 menschlichen Gene monogene Krankheiten auslösen können (Cooper et al., 2010), wie bereits einleitend erwähnt. Zytogenetisch erkennbare und submikroskopische Chromosomenveränderungen, die man durch Array-CGH identifizieren kann, sind für 15 bis 20 Prozent aller ernsten genetisch bedingten Störungen verantwortlich. Wie jüngste Untersuchungen 
gezeigt haben, kann man die allermeisten dieser Veränderungen auch durch NGS identifizieren und charakterisieren (Gilissen et al., 2014). ${ }^{29}$

Auch im Bereich der Onkologie, vor allem in der Hämato-Onkologie, hat sich die DNA-Sequenzierung als genetisches Diagnostikverfahren etabliert: Die Krebsdiagnostik erfasst hier spezifische Mutationen in bestimmten Tumorgenen, aus denen sich Therapiemöglichkeiten und Aussagen zum Behandlungsverlauf ableiten lassen. Pharmakogenetische Untersuchungen gehören in den Bereich der sogenannten personalisierten Medizin. Sie zielen auf die Abklärung von individuellen genetischen Merkmalen, die einen Einfluss auf die Wirksamkeit, Verträglichkeit oder optimale Dosierung von Wirkstoffen haben. Prädiktive Tests können im Gegensatz zu diagnostischen Tests individuelle Risiken für Krankheiten abklären, die sich voraussichtlich manifestieren werden. Erbkrankheiten in der Familie oder auch auffällige Häufungen von Tumorerkrankungen können zum Beispiel ein Indiz für ein erhöhtes genetisches Risiko sein. Prädiktive Tests erlauben eine Erkennung relevanter genetischer Risikovarianten vor der Manifestation klinischer Symptome und damit auch eine frühzeitige Begleitung und Behandlung der Betroffenen. Neben der eigentlichen Diagnose sind für viele Betroffenen vor allem ihr individuelles Erkrankungsrisiko und die Informationen zum möglichen Krankheitsverlauf von Bedeutung. Eine genetische Familienberatung bei Kinderwunsch wird bisher nur bei Vorliegen einer spezifischen Indikation durchgeführt, etwa nach der Diagnose einer chromosomalen Translokation oder einer rezessiven Krankheit bei einem Kind, bei Blutsverwandtschaft der Eltern, nach mehrfachen Fehlgeburten oder bei unerfülltem Kinderwunsch ohne erkennbare gynäkologische oder andrologische Ursachen. Mithilfe NGS-gestützter Tests ist es im Prinzip möglich, elterliche Risikokonstellationen für bekannte rezessive Gendefekte schon vor der Konzeption zu erkennen, auch wenn diese Untersuchungen einen weit größeren Aufwand erfordern als die molekulare Diagnostik an betroffenen Patienten (Umbarger et al., 2014; vgl. auch Dewey et al., 2014). Dieses Risiko ${ }^{30}$ darf nicht unterschätzt werden: Bei gesunden Probanden westlicher Industriestaaten wurden im Durchschnitt Anlagen für drei bekannte rezessive Krankheiten festgestellt (Bell et al., 2011; Gonzales-Garay et al., 2013); und unter der Annahme, dass 0,25 bis 0,5 Prozent aller Neugeborenen in dieser Bevölkerungsgruppe

29 Vgl. zu den verschiedenen Formen genetisch (mit)bedingter Krankheiten ausführlicher etwa den „Ersten Gentechnologiebericht“ (Hucho et al. 2005:162 ff.).

30 Bei Patienten mit autosomal-rezessiven Erkrankungen sind beide Kopien eines bestimmten Gens defekt, und in den allermeisten Fällen sind beide Eltern Träger einer defekten Genkopie. Das Erkrankungsrisiko für Kinder zweier Anlageträger beträgt 25 Prozent. Mithilfe eines Heterozygotentests bei Paaren mit Kinderwunsch kann man solche Konstellationen rechtzeitig erkennen bzw. ausschließen. 
an rezessiven Störungen leiden, liegt eine derartige Risikokonstellation bei ein bis zwei Prozent aller Eltern vor. ${ }^{31}$

Genetische Tests sind auch in der Schwangerschaft möglich (pränatale Diagnostik, PND). Im Rahmen vorgeburtlicher Diagnostik werden bei abweichender fetaler Entwicklung oder anderen Indikationen - wie einem fortgeschrittenen Alter eines oder beider Partner - auch ausgewählte genetische Erkrankungen abgeklärt. Auch im Anschluss an die künstlichen Fortpflanzungsmethoden werden unter Umständen genetische Tests eingesetzt: Die Präimplantationsdiagnostik (PID) beschreibt die genetische Untersuchung eines Embryos nach erfolgreicher In-vitro-Fertilisation, um eine wahrscheinliche und schwerwiegende Erbkrankheit zu diagnostizieren und bei einer anschließenden Implantation durch Auswahl zu vermeiden. Die vorgeburtliche Diagnostik - PND wie auch PID - stellt einen sehr sensiblen Bereich genetischer Diagnostik dar, der Lebensinteressen und Lebensqualität von Eltern und Kind miteinander verknüpft und hohe ethische und rechtliche Anforderungen stellt, auf die im folgenden Abschnitt noch näher eingegangen wird.

Einen besonderen Stellenwert im Hinblick auf eine bevölkerungsbezogene Gesundheitsfürsorge nimmt auch die systematische Früherkennung von genetischen Krankheiten mittels Reihenuntersuchungen (Screenings) ohne individuelle klinische Indikation ein. Es kann sich dabei sowohl um die Gesamtbevölkerung wie auch um umschriebene Bevölkerungsgruppen handeln. Beim Neugeborenen-Screening in Deutschland wird eine begrenzte Zahl angeborener hormoneller Störungen und Stoffwechselerkrankungen erfasst, allerdings nicht auf DNA-Ebene (BBAW, 2013:24). In anderen Bevölkerungen ist das Heterozygoten-Screening zur Prävention häufiger rezessiv vererbter Störungen schon seit Jahrzehnten fester Bestandteil der Krankheitsvorsorge. ${ }^{32}$

\subsubsection{HDS in der klinisch-genetischen Diagnostik}

Gegenwärtig sind HDS-gestützte gendiagnostische Verfahren - ob Panelsequenzierungen oder medizinische Genomsequenzierung in Form von WES/WGS (s. o.) - in Deutschland noch keine kassenärztliche Leistung. Stattdessen müssen auffällige Befunde in der Regel stufenweise („Gen für Gen“) über klassische Verfahren, zum Beispiel mittels

31 Vgl. hier auch die gemeinsame Stellungnahme von Leopoldina, acatech und BBAW zur „Prädiktive[n] genetische[n] Diagnostik als Instrument der Krankheitsprävention“ vom November 2010. Unter: www.leopoldina.org/uploads/tx_leopublication/201011_natEmpf_praedikative-DE.pdf [10.07.2014].

32 Vgl. z. B. Programme zur Prävention von Beta-Thalassämie: http://www.bpb.de/veranstaltungen/dokumentation/129724/die-praevention-von-thalassaemie-auf-zypern [02.06.2014] oder der TaySachs-Krankheit: https://www.jewishgenetics org/dor-yeshorim [05.06.2014]. 
Sanger-Sequenzierung, abgeklärt werden - auch wenn diese Praxis in vielen Fällen außerordentlich verzögert oder sogar nie zu einer definitiven Diagnose führt und mit erheblich höheren Kosten verbunden ist. ${ }^{33}$

Jedoch hat die schrittweise Einführung der Hochdurchsatz-Sequenzierung in die genetische Diagnostik schon in den USA, in Europa und sogar partiell in Deutschland begonnen. Bereits seit einiger Zeit sind private Krankenversicherungen und gesetzliche Kostenträger dazu übergegangen, Anträge auf Kostenübernahme für derartige Untersuchungen entgegenzunehmen und nach positiver Einzelfallprüfung zu bewilligen. Im Rahmen einer großen Pilotstudie werden in den Niederlanden bereits seit zwei Jahren WES- und WGS-gestützte diagnostische Untersuchungen an Erkrankten und ihren Eltern von den Krankenkassen (teil)finanziert (vgl. van Zelst-Stams et al., 2014), und im Rahmen des staatlichen, vom britischen Premierminister Cameron im Dezember 2012 inaugurierten „Genomics England“-Projekts ${ }^{34}$ ist die Sequenzierung von insgesamt hunderttausend Genomen bis Ende 2017 geplant. Das Programm soll nicht nur das Potenzial der HDS-Techniken zur Verbesserung der Patientenversorgung in Großbritannien ausloten, sondern auch die Übertragung von Forschungsergebnissen in klinische Anwendung befördern. In den USA haben mehrere große Kliniken mit der Einführung der medizinischen Genomsequenzierung als diagnostischem Eingangstest für - vor allem pädiatrische - Fälle mit unklaren Störungen begonnen.

\subsubsection{Medizinische Genomsequenzierung für monogene Erkrankungen}

Die HDS-gestützte Gendiagnostik zielt vor allem auf seltene monogene Erkrankungen, denen viele verschiedene molekulare Ursachen zugrunde liegen können und die sich aufgrund ihrer (sehr ähnlichen) Symptomatik klinisch nicht oder nur schwer unterscheiden lassen. In diese Kategorie fallen zum Beispiel unklare psychomotorische Entwicklungsstörungen im Kindesalter. Diese Krankheitsgruppe allein gibt Veranlassung für fast die Hälfte aller genetischen Beratungen in Deutschland (BBAW, 2013:11). ${ }^{35}$

Mithilfe herkömmlicher Protokolle, welche die klinische Untersuchung ins Zentrum der genetischen Diagnostik stellen, dauert es bei seltenen Krankheiten bis zur Diagno-

33 Auch lassen sich bestimmte HDS-Befunde, z. B. Heterozygotie für Deletionen, deren Grenzen nicht genau bekannt sind, nicht mittels Sanger-Sequenzierung validieren.

34 http://www.genomicsengland.co.uk/ [25.06.2014]. Das Projekt befindet sich noch in seiner Pilotphase und ist initial auf seltene Krankheiten ausgerichtet.

35 Oft werden diese Störungen nicht von den Eltern vererbt, sondern sie entstehen spontan (vgl. Rauch et al., 2012; de Ligt et al., 2012). Eine präkonzeptionelle Diagnostik derartiger Neumutationen 
sestellung in der Regel mehrere Jahre, und in circa 40 Prozent der Fälle ist die erste Diagnose nach Erhebungen der Patientenorganisation EUROCORDIS ${ }^{36}$ falsch. Die Einführung der medizinischen Genomsequenzierung als diagnostischer Eingangstest bei unklaren, möglicherweise genetisch bedingten Störungen verspricht, den Zeitraum bis zur Diagnose auf wenige Wochen zu verkürzen. Für die Betroffenen und ihre Familien endet damit oft eine jahrelange Odyssee von Arzt zu Arzt, und die korrekte Diagnose ermöglicht zum ersten Mal eine Prognose zum Krankheitsverlauf, den Austausch mit anderen betroffenen Patienten und Familien sowie in vielen Fällen eine verbesserte Betreuung und Versorgung, auch wenn es bislang nur für wenige dieser Krankheiten wirkliche therapeutische Optionen gibt. ${ }^{37}$ Zudem eröffnet eine eindeutige genetische Diagnose vielen Paaren bei folgenden Schwangerschaften die Möglichkeit einer Pränataldiagnose.

Für gendiagnostische Untersuchungen gilt es - wie generell für alle medizinischen Anwendungen -, den klinischen Nutzen zu bewerten, worauf im „Zweiten Gentechnologiebericht“ (Müller-Röber et al., 2009:125 ff.) ausführlich eingegangen wurde. Die Erarbeitung von Indikationskriterien zur Bewertung der Validität (und des klinischen Nutzens) genetischer Tests, wie sie von der Deutschen Gesellschaft für Humangenetik (GfH) begonnen wurde, ist in der dritten Berichtsphase auf europäischer Ebene gebündelt worden (Schmidtke/Cassiman, 2010)..$^{38}$ Eine Auflistung aller genetisch bedingten Defekte, für die eine molekulare Diagnostik möglich und sinnvoll ist, erscheint in Anbetracht der mittlerweile hohen Anzahl bekannter krankheitsrelevanter Gene allerdings überholt.

Verschiedene Studien haben das diagnostische Potenzial der medizinischen Genomsequenzierung inzwischen auf überzeugende Weise belegt. So konnten zum Beispiel durch Whole Exome Sequencing (WES) bei 1.200 Kindern mit schweren Störungen unklarer Genese und deren Eltern bei etwa einem Viertel der Fälle relevante Veränderungen in bekannten Krankheitsgenen identifiziert und damit eine eindeutige molekulare Diagnose gestellt werden (Yang et al., 2013). Zusätzlich wurden in einem hohen Prozentsatz Neumutationen gefunden - oft in Genen, für die bisher kein Krankheitsbezug bekannt war (vgl. van Zeist-Stam et al., 2014). Immer schneller gelingt sogar

36 www.eurordis.org [10.07.2014].

37 Eine kausale Therapie ist derzeit erst bei einem geringen Prozentsatz seltener genetisch bedingter Krankheiten möglich. Jedoch gibt es bereits für $>500$ der bekannten Gendefekte unterstützende Maßnahmen, die Betroffenen den Umgang mit ihrer Krankheit erleichtern.

38 Koordiniert über das EU-finanzierte EuroGentest-Projekt, vgl. https://eurogentest.eshg.org [26.06.2014]. Empfehlungen für gendiagnostische Tests werden von ausgewählten internationalen Sachverständigenteams erarbeitet und seit 2010 in Form von „clinical utility gene cards” (CUGCs) im European Journal of Human Genetics. (EJHG) yeröffentlicht. Stand Juni 2014:118 fertiggestellte CUGCs. 
der Nachweis, dass erstmalig beobachtete DNA-Veränderungen für die betreffenden Krankheitsbilder ursächlich verantwortlich sind: in den meisten Fällen durch Identifikation von Mutationen desselben Gens in klinisch ähnlichen Fällen (z. B. Najmabadi et al., 2011; de Ligt et al., 2012; Rauch et al., 2012; Bainbridge et al., 2013), aber auch durch Abgleich des klinischen Bildes mit dem Phänotyp von Tiermodellen, die Mutationen in orthologen Genen aufweisen, oder durch funktionelle Untersuchungen in zellulären Systemen. Jüngste Befunde an Patienten mit geistiger Behinderung sprechen dafür, dass sich die diagnostische Ausbeute derartiger Untersuchungen durch Einführung des Whole Genome Sequencing (WGS) auf deutlich über 50 Prozent steigern lässt, wie bereits oben angedeutet (Gilissen et al., 2014). Ein ähnlich hoher Prozentsatz aufgeklärter Fälle wurde bei einer kanadischen WES-Studie zur Aufklärung seltener Gendefekte gefunden (Beaulieu et al., 2014).

Diese Beobachtungen sprechen dafür, dass es durch medizinische Genomsequenzierung und allfällige ergänzende Untersuchungen möglich ist, bei circa der Hälfte aller Erkrankten mit begründetem Verdacht auf genetisch bedingte Störungen innerhalb weniger Wochen eine eindeutige molekulare Diagnose zu stellen. Eine noch höhere diagnostische Ausbeute und damit eine weitere Verbesserung der genetischen Diagnostik wird sich nur durch Identifizierung zusätzlicher, bisher unbekannter Krankheitsgene erreichen lassen. Das ist ein starkes Argument für die rasche Einführung der medizinischen Genomsequenzierung (und insbesondere der WGS) als diagnostisches Standardverfahren im Bereich der genetischen Krankenversorgung.

\subsection{Genetisches Wissen als Herausforderung}

In der medizinischen Genetik wird Probanden ein Recht auf Wissen ebenso zugestanden wie ein Recht auf Nichtwissen, obwohl es zwischen beiden Rechten zu Kollisionen kommen kann, zum Beispiel wenn es um die Diagnose von genetischen Erkrankungen innerhalb von Familien geht. Dieses Problem -, und unter einer breiteren Perspektive die Frage nach dem Umgang mit genetischen Daten - hat durch die Genomsequenzierung eine wesentliche Zuspitzung erfahren. Trotz der in Deutschland eindeutigen gesetzlichen Vorgaben steht die Frage im Raum, ob jeder direkten Zugang zu eigenen genetischen Befunden und zu medizinischen Hintergrundinformationen erhalten sollte oder ob zu deren Vermittlung ein persönliches Gespräch mit einem Arzt zwingend erforderlich ist. Dabei ist zu berücksichtigen, dass auch unter Medizinern die genetischen Kenntnisse stark variieren und dass sich bereits heute schon etwa 80 Prozent aller Internetnutzer zu Gesundheitsfragen eigenständig über dieses Medium informieren (Krüger-Brand, 2009). 
In den USA hat sich die restriktive Haltung der Food and Drug Administration (FDA) und staatlicher Stellen gegenüber Firmen verstärkt, die sich seit circa sieben Jahren mit dem Angebot einer auf die Typisierung von DNA-Markern gestützten Genomanalyse direkt an interessierte Kunden richten (Direct-to-Consumer-Tests, DTC). Trotz einer Anhörung im amerikanischen Kongress und der weit verbreiteten Kritik, die angebotenen Tests seien irreführend und als Indikatoren für spezifische Gesundheitsrisiken praktisch wertlos, hatte die Firma 23andMe als einziger der früher führenden Anbieter solcher Tests an ihrem Geschäftsmodell und ihrem Credo festgehalten, dass Menschen ein fundamentales Recht auf die in ihrer DNA enthaltenen Informationen haben (BBAW, 2013:24). Nach einer im August 2013 im Fernsehen gestarteten landesweiten Werbekampagne für einen von der Firma vertriebenen Speicheltest zum Ausschluss „eines erhöhten Risikos für Herzkrankheiten, Arthritis, Gallensteinen (oder) Hämochromato$\mathrm{se}^{\text {“39 }}$ hat die FDA den Vertrieb dieses Tests im November 2013 mit unmittelbarer Wirkung untersagt, solange, bis eine offizielle Zertifizierung vonseiten der FDA vorliegt.

Nach anfänglicher, teilweise heftiger Kritik an dieser „fortschrittsfeindlichen“ Entscheidung scheint sich jetzt die Meinung durchzusetzen, dieses Verbot sei eine Gelegenheit für einen ernsthaften Dialog, welcher zu einheitlichen Standards der gesamten DTC-Industrie führen könne (Annas/Elias, 2014). Im Hinblick auf diese Entwicklung erscheint die in Deutschland zu beobachtende Tendenz zur grundsätzlichen Ablehnung des DTC-Modells und der Übermittlung genetischer Informationen „direkt an den Kunden“ überzogen, wie bereits früher angemerkt (BBAW, 2013:26). Einige der auf diesem Gebiet tätigen Firmen haben äußerst elaborierte Verfahren entwickelt, um Betroffenen und Familienangehörigen die klinische Relevanz und Tragweite solcher Befunde verständlich zu machen, unter Einhaltung des Datenschutzes und größtmöglicher Berücksichtigung des Rechts auf Wissen und Nichtwissen. Sie könnten daher in Zukunft Vorreiter sein bei der Entwicklung neuer Verfahren zur Weitergabe genetischer Informationen, die angesichts der sich abzeichnenden Datenflut als Folge der medizinischen Genomsequenzierung für die gesamte genetische Diagnostik unentbehrlich werden.

Während der Abgleich potenziell pathogener Sequenzvarianten mit dem klinischen Bild des Patienten einschlägige medizinische Fachkenntnisse voraussetzt, gilt dies nicht für die Genomsequenzierung selbst und nur zum Teil für die Identifikation potenziell relevanter Varianten. Verschiedentlich hat das im Bereich der medizinischen Genomsequenzierung zu einer Aufgabenteilung zwischen Genomzentren und klinischgenetischen Zentren geführt. So in den USA, wo Nutzer dieser Technologie zwischen verschiedenen Genomzentren und anderen großen, kommerziell operierenden Anbie- 
tern wählen können. Vor diesem Hintergrund hat sich das American College of Medical Genetics (ACMG) bis vor Kurzem mit dem Problem auseinandergesetzt, ob und in welchem Umfang Genomzentren verpflichtet sind, im Zuge der Genomsequenzierung erhobene Nebenbefunde den behandelnden Ärzten (und implizit den Probanden) mitzuteilen. In diesem Zusammenhang wurde eine Positivliste von 56 Gendefekten publiziert (Green et al., 2013). Nach zum Teil hitzigen Diskussionen hat das ACMG inzwischen seine Position überdacht und Probanden das Recht eingeräumt, vor Beginn der Genomsequenzierung anhand eines Fragebogens zu definieren, bei welcher Art von Befunden sie von ihrem Recht auf Nichtwissen Gebrauch machen wollen. ${ }^{40}$ In Europa hatte man diese Möglichkeit zum Umgang mit unvorhergesehenen Befunden (,incidental findings“) schon früher ausführlich diskutiert und das Problem dieser „Überschussinformationen" damit weitgehend entschärft (BBAW, 2013:28). Überdies hat sich inzwischen herausgestellt, dass unvorhergesehene Befunde deutlich seltener vorkommen als früher befürchtet. Die in unserer Bevölkerung nicht seltene Furcht vor dem eigenen Genom ist daher weitgehend unbegründet. ${ }^{41}$

\subsection{Genomsequenzierung als Dienstleistung: Konsequenzen für die genetische Krankenversorgung}

Die seit Anfang 2014 erfolgte und für die nahe Zukunft angekündigte Inbetriebnahme einer Vielzahl von Höchstdurchsatz-Sequenziersystemen der Firma Illumina hat weltweit zu einer Überkapazität bei der Sequenzierung menschlicher Genome und fast zeitgleich zu drastischen Kostensenkungen geführt. Mit der Auslieferung der ersten Systeme dieser Art an nationale Genforschungs- und Diagnostikzentren wurde auch der Plan des bisher größten Anbieters auf diesem Gebiet, BGI/Complete Genomics, unterlaufen, eine weltweit einzigartige Datenbank für krankheitsassoziierte Genomvarianten aufzubauen und diese kommerziell zu nutzen. ${ }^{42}$ Aufgrund der erklärten Absicht von BGI/ Complete Genomics, in nächster Zukunft ein eigenes Höchstdurchsatz-Sequenziersystem zu vertreiben, dürfte die Überkapazität in absehbarer Zeit eher zu- als abnehmen. Mit Preiserhöhungen bei der Genomsequenzierung ist demzufolge eher nicht zu rechnen, und aufgrund der zunehmenden Zahl installierter Systeme muss man nicht mehr befürchten, von einzelnen Anbietern und ihren Datenbanken abhängig zu werden. Da-

40 www.bio-itworld.com/2014/4/1/acmg-changes-recommendations-incidental-findings-optingout.html [11.07.2014].

41 Siehe hier Ropers: 2012 b; Church, 2013.

42 Vgl. Ropers, 2013 oder das Interview mit Wang Jun, BGI, in der South China Morning Post am 16.12.2013. 
mit entfällt für die allermeisten Nutzer die Notwendigkeit, eine eigene Infrastruktur für die Hoch- oder gar Höchstdurchsatz-Sequenzierung aufzubauen. Angesichts der hohen Beschaffungs- und Betriebskosten und der wahrscheinlich kurzen technischen Halbwertszeit dieser Systeme ist das eine gute Nachricht.

Zurzeit (Juli 2014) ist es nur mithilfe von Sequenziersystemen der beiden Marktführer Illumina und BGI/Complete Genomics möglich, Rohsequenzen menschlicher Genome für kaum mehr als 1.000 US-Dollar zu erzeugen, was bei diesem Aspekt der Ganzgenomsequenzierung zu einer weitgehenden Standardisierung geführt hat. Demgegenüber gibt es für die Suche nach krankheitsverursachenden Mutationen in diesen Sequenzen eine Vielzahl verschiedener bioinformatischer Spezialsoftware und Programmbausteine, aber bisher keine optimale, allgemein akzeptierte Lösung. Gleiches gilt für die Beschreibung und Katalogisierung klinischer Phänotypen, auch wenn in beiden Bereichen in jüngerer Zeit sichtbare Fortschritte erzielt wurden. Eine Optimierung dieser Verfahren und die Einigung auf gemeinsame Datenformate und Standards ist eine essentielle Bedingung für die erfolgreiche Zusammenführung dieser Informationen in zentralen Datenbanken. Diese sind für die Identifizierung krankheitsassoziierter Genomveränderungen und neuer Krankheitsgene unverzichtbar, und ihre Etablierung dient damit nicht nur der Verbesserung der genetischen Diagnostik, sondern ist auch für die Aufklärung der Pathogenese von Krankheiten und die Entwicklung neuer Medikamente von zentraler Bedeutung. Der Wert und praktische Nutzen derartiger Datenbanken hängen jedoch entscheidend von der Qualität der darin gespeicherten Daten ab.

Die Interpretation und Validierung der bei der medizinischen Genomsequenzierung anfallenden großen Datenmengen, aber auch die Etablierung und Überwachung einheitlicher Qualitätsstandards im Bereich der klinischen Genetik stellen höchste Anforderungen an die verfügbare bioinformatische, genetische und klinische Infrastruktur. Daher sind nur entsprechend ausgerüstete, kompetente und vernetzte genetische Zentren für die Durchführung derartiger diagnostischer Untersuchungen qualifiziert, wie früher ausgeführt (BBAW, 2013:34). Auch aus Gründen des Datenschutzes ist die Begrenzung der medizinischen Genomsequenzierung auf wenige Zentren sinnvoll, wie ebenfalls früher ausgeführt (BBAW, 2013:28), ebenso zur bundesweiten Erfassung und Koordination dieser diagnostischen Aktivitäten, der Etablierung einheitlicher Standards bei der Indikationsstellung und nicht zuletzt als Regulativ zur Verhinderung exorbitanter Kostensteigerungen. Jüngste Vorschläge einschlägiger Berufsverbände zur zukünftigen Tarifstruktur in diesem Bereich belegen nicht nur deren großes Interesse an der HDS-gestützten Gendiagnostik, sondern auch die Notwendigkeit einer stringenten und sachgerechten Kostenkontrolle auf diesem Gebiet. 
Wie verschiedene Untersuchungen gezeigt haben, ist die Sequenzierung vollständiger menschlicher Genome (WGS) der Exomsequenzierung (WES) als Methode zur Identifizierung genetischer Krankheitsursachen überlegen. Seit der Einführung von Höchstdurchsatz-Sequenziersystemen und der dadurch ausgelösten Kostensenkung zeichnet sich ab, dass die WGS die WES im Bereich der Gendiagnostik weitaus schneller verdrängen wird, als noch vor Kurzem erwartet (Ropers, 2012 a), und auf längere Sicht könnte sie sogar die Sequenzierung großer Genpanels ersetzen, wie oben erwähnt. Einer weiten Verbreitung dieser neuen Sequenziertechnologie standen neben hohen Beschaffungskosten jedoch zunächst Lieferengpässe des amerikanischen Geräteherstellers Illumina im Weg. Parallel dazu hat die Nachricht, die von der Firma BGI/Complete Genomics erhobenen Sequenzdaten würden zum Aufbau einer eigenen Datenbank verwendet, bei Nutzern dieses Sequenzierservice zu einer spürbaren Zurückhaltung geführt.

Aufgrund der enormen Kapazität des Illumina-Systems ist es jedoch bei den beiden ersten Betreibern ${ }^{43}$ bereits zu Auslastungsproblemen gekommen, in deren Folge sich beide entschlossen, die freien Kapazitäten ihrerseits für einen kommerziellen Sequenzierservice zu nutzen. Dadurch und durch die sich abzeichnende Überkapazität anderer Betreiber wird die Genomsequenzierung inzwischen für kaum mehr als 1.000 Euro, also quasi zu Selbstkosten angeboten.

Damit steht die Nutzung dieses Angebots im Prinzip allen Humangenetikern offen, unabhängig von der vorhandenen Infrastruktur und Expertise im Umgang mit menschlichen Genomsequenzen, der Analyse dieser Daten und ihrer Erfahrung bei der klinischen Bewertung möglicherweise pathogener Sequenzvarianten. Diese Entwicklung könnte die Bemühungen zur Verbesserung der genetischen Krankenversorgung durch Schaffung klinisch-genetischer, bevorzugt an Universitätskliniken angesiedelter Kompetenzzentren konterkarieren, die gegenwärtige Schieflage im Verhältnis zwischen universitären und niedergelassenen Humangenetikern zementieren und die Chance vereiteln, dass Deutschland bei der genetischen Diagnostik und Genomforschung Anschluss an die Standards der in Europa auf diesem Gebiet führenden Länder gewinnt.

Den bislang wenigen auf dem Gebiet der medizinischen Genomsequenzierung ausgewiesenen Zentren für klinische Genetik und seltene Erkrankungen kommt daher jetzt die Aufgabe zu, die Instrumente und Verfahren für die routinemäßige Anwendung der WGS im Rahmen der genetischen Diagnostik zu optimieren und den medizinischen und ökonomischen Nutzen der WGS unter Beweis zu stellen. Parallel dazu sind Politik und 
Krankenversicherungen aufgerufen, dafür zu sorgen, dass diese neuen Methoden nur dort im Rahmen der genetischen Diagnostik genutzt und finanziert werden, wo die für die adäquate Auswertung und Beurteilung dieser Daten erforderliche Infrastruktur und Expertise vorhanden sind. Nur dadurch kann die Qualität der erhobenen klinischen und molekularen Befunde und ihre Zusammenführung in einer zentralen Datenbank sichergestellt werden, nach dem Beispiel bereits existierender Datenbanken in Großbritannien, Kanada und den USA. ${ }^{44}$

\subsection{Rechtliche und politische Aspekte}

Die oben dargestellten Entwicklungen seit dem Erscheinen des „Zweiten Gentechnologieberichts“ werfen eine Reihe politischer und rechtlicher Fragen auf. Angesichts der Bedeutung des Whole Genome Sequencing für die Krankenversorgung, aber auch für die Medikamentenentwicklung und damit für die Pharmaindustrie, gilt es zu klären, ob und in welchem Umfang die Politik bei der klinischen Einführung dieser Methoden gefordert ist oder ob es vertretbar ist, die Entscheidung darüber den primär betroffenen Parteien, das heißt der Ärzteschaft, deren Kammern und Standesorganisationen sowie anderen Leistungserbringern, den Spitzenverbänden der Kostenträger und dem Gemeinsamen Bundesausschuss zu überlassen. Angesichts der Interdependenz von (überwiegend staatlich finanzierter) Genomforschung und (überwiegend von den Kostenträgern des Gesundheitswesens finanzierter) Gendiagnostik stellt sich auch die Frage, in welchem Umfang diese Parteien an der Finanzierung beteiligt werden sollten und welche Forschung in diesem Zusammenhang überhaupt unterstützenswert ist.

Auch der oben skizzierte Umgang mit dem Recht auf Wissen und Nichtwissen steht immer wieder zur Diskussion. Vor dem Hintergrund politisch gewollter Harmonisierung auf europäischer Ebene gilt es zudem, das Verhältnis zwischen deutscher Rechtsordnung und transnationalen Vorgaben auszuloten. Auf dem Gebiet der Gendiagnostik gelten mehrheitlich nationale Regelungen und Gesetze, jedoch nicht ausschließlich. Zum Beispiel enthalten einschlägige UNESCO-Deklarationen Vorgaben für Bereiche der Gendiagnostik, die durch das Gendiagnostikgesetz und andere Gesetze in Deutschland nicht geregelt sind (vgl. Deutscher Ethikrat, 2013:110). In diesem Zusammenhang soll auch das Embryonenschutzgesetz (ESchG) und die seit 2014 geltende Neuregelung der Präimplantationsdiagnostik erwähnt werden, auch wenn die präkonzeptionelle und die pränatale Diagnostik nicht im Mittelpunkt dieser Ausführungen stehen. 
Allgemein bildet in der Bundesrepublik Deutschland das Sozialgesetzbuch V ( $\$ 70$ und § 135 ff. SGB V) die gesetzliche Grundlage für den Auftrag zur Qualitätssicherung medizinischer Leistungen. Unterschieden wird hier, ob die jeweilige Untersuchung zur Therapieplanung oder zur sonstigen genetischen Untersuchung angewandt werden soll. Sofern die angestrebte Diagnostik über eine eigene Gebührenordnungsposition (GOP) verfügt, zählt sie zur vertragsärztlichen Versorgung.

Das im Jahre 2009 (im Bundesgesetzblatt 2009 Teil I Nr. 50) veröffentlichte und ein Jahr später in Kraft getretene Gendiagnostikgesetz (GenDG) regelt den Umgang mit prä- und postnatalen, diagnostischen und prädiktiven Untersuchungen am Menschen. Es bezweckt, „,ie Voraussetzungen für genetische Untersuchungen zu bestimmen und eine Benachteiligung auf Grund genetischer Eigenschaften zu verhindern, um insbesondere die staatliche Verpflichtung zur Achtung und zum Schutz der Würde des Menschen und des Rechts auf informationelle Selbstbestimmung zu wahren“ ( 1 GenDG). Neben einer der Untersuchung vorausgehenden Aufklärung ( 9 GenDG) und einer schriftlichen Einwilligungserklärung schreibt das GenDG eine anschließende genetische Beratung vor ( $\$ 10 \mathrm{GenDG}$ ). Daneben enthält es die Bestimmung, dass eine diagnostische genetische Untersuchung nur durch Ärzte und eine prädiktive genetische Untersuchung nur durch Fachärzte für Humangenetik oder andere Ärzte vorgenommen werden darf, die sich beim Erwerb einer Facharzt-, Schwerpunkt- oder Zusatzbezeichnung für genetische Untersuchungen im Rahmen ihres Fachgebietes qualifiziert haben. Dieser Passus berücksichtigt weder die Tatsache, dass nur ein Teil der im Rahmen der Genomsequenzierung anfallenden Tätigkeiten medizinische Kenntnisse voraussetzt, noch erlaubt er die Einbindung erfahrener nichtärztlicher Humangenetiker in den Beratungsprozess, um den akuten Mangel an erfahrenen Fachärzten für Humangenetik abzumildern; den oben dargestellten aktuellen Erfordernissen der medizinischen Genomsequenzierung trägt er daher nicht angemessen Rechnung.

Seit dem Inkrafttreten des GenDG ist die Gesellschaft für Humangenetik in den vergangenen Jahren mit einer Vielzahl von Stellungnahmen zu verwandten Themen an die Öffentlichkeit getreten, zuletzt mit einer Leitlinie zur humangenetischen Diagnostik und genetischen Beratung, und die vom Bundesministerium für Gesundheit auf der Grundlage des Gendiagnostikgesetzes eingesetzte, interdisziplinäre Gendiagnostik-Kommission hat seit 2009 verschiedene Richtlinien zu diesem Themenbereich veröffentlicht.

Vermutlich aufgrund interner Interessengegensätze sind die Gesellschaft für Humangenetik und die Gendiagnostik-Kommission, aber auch der Deutscher Ethikrat in den vergangenen Jahren einer Kritik an der Organisation und Aufgabenverteilung im Bereich der Gendiagnostikin Deutschland aus dem.Weg gegangen. Einzig die BBAW hat 
sich in ihrer Stellungnahme aus dem Jahre 2013 zu diesem Thema geäußert. Sie empfiehlt die Einführung der medizinischen Genomsequenzierung, allerdings ausschließlich an speziell dafür ausgewiesenen universitären Zentren für seltene Krankheiten mit entsprechender personeller und apparativer Infrastruktur. Eine derartige Konzentration der genetischen Diagnostik sei auch angesichts der unüberschaubar großen Zahl genetischer Störungen unumgänglich, deren Vielfalt selbst die Kompetenz der besten genetischen Syndromologen und klinischen Genetiker übersteigt. Daher sei die genetische Krankenversorgung nur im Team möglich (BBAW, 2013:27). Angesichts der Hinweise auf eine baldige Einführung der WGS als universeller diagnostischer Test im Bereich der genetischen Krankenversorgung sind diese Empfehlungen aktueller denn je.

\subsection{Fazit}

Nicht die angekündigte Entwicklung innovativer Sequenzierungstechniken der „übernächsten“ Generation, sondern die Etablierung von Höchstdurchsatz-,,Sequenzierfabriken“ auf der Grundlage etablierter Technologien hat seit Anfang 2014 zu einer dramatischen Senkung der Kosten für die Sequenzierung vollständiger menschlicher Genome (Whole Genome Sequencing, WGS) geführt. Aufgrund weltweiter Überkapazitäten ist die WGS inzwischen im Begriff, zu einer allgemein verfügbaren kommerziellen Dienstleistung zu werden. Damit sind zwei wesentliche Voraussetzungen für die breite Nutzung der WGS als universeller diagnostischer Test erfüllt, mit dem man nicht nur alle bekannten Gendefekte, sondern im Prinzip sämtliche krankheitsrelevanten Genomveränderungen identifizieren oder ausschließen kann. Der wichtigste limitierende Faktor dabei ist unsere rudimentäre Kenntnis der Pathogenität neuer, zum ersten Mal beobachteter Genomvarianten. Diese Wissenslücke lässt sich nur nach und nach schließen, am einfachsten durch Einführung der WGS als klinischem Eingangstest für Patienten mit unklaren, vermutlich genetisch bedingten Störungen und durch Sammlung aller beobachteten Sequenzvarianten und klinischen Befunde in einer zentralen Datenbank. In ausgewiesenen klinisch-genetischen Zentren mit hinreichender Infrastruktur und Erfahrung bei der Analyse und klinischen Interpretation genomischer Daten ermöglicht die WGS bereits heute in etwa der Hälfte aller Fälle eine eindeutige Diagnose.

Die Einführung der WGS ist daher eine enorme Chance zur Verbesserung der genetischen Diagnostik und Krankenversorgung, insbesondere für Länder, in denen die genetische Diagnostik ausschließlich an derartigen hochqualifizierten Zentren durchgeführt und vergütet wird. Für die genetische Krankenversorgung in Deutschland, wo die meisten relevanten Patientenkontakte auf niedergelassene Fachärzte für Humangenetik entfallen und der Aufbawvon Zentren für seltene Krankheiten nur langsam vor- 
ankommt, stellt die sich abzeichnende freie Verfügbarkeit der WGS jedoch eine ernste Bedrohung für die Qualität und Kostenkontrolle im Bereich der genetischen Diagnostik dar. Es steht zu befürchten, dass diese Entwicklungen die überfällige Konzentration der genetischen Diagnostik an ausgewiesenen klinisch-genetischen Kompetenzzentren unterlaufen und zu einer Zementierung der bestehenden dezentralen Organisationsstrukturen führen werden. Letztere tragen maßgeblich dazu bei, dass Deutschland auf diesem Gebiet der Krankenversorgung und medizinischen Forschung keine seiner wissenschaftlichen und wirtschaftlichen Potenz angemessene Rolle spielt. Das kann und muss sich ändern, und sowohl die Bundesregierung als auch die Kostenträger sind aufgerufen, die dafür notwendigen regulierenden Maßnahmen zu ergreifen.

Besonderer Dank gilt an dieser Stelle Thomas Wienker für die sorgfältige und fachkundige Durchsicht des Manuskripts und seine hilfreichen Korrekturvorschläge.

\subsection{Problemfelder und Indikatoren im Bereich der Gendiagnostik}

\subsubsection{Einführung und Übersicht}

Um die komplexen Diskussionsstränge in der öffentlichen Debatte rund um die Entwicklungen im Bereich Gendiagnostik sichtbar und mittels belastbarer Indikatoren auch quantitativ messbar zu machen, erfolgte dabei analog der in Kapitel 2 beschriebenen Methodik die Erhebung eines Text-Korpus ${ }^{45}$ : Die recherchierten Texte wurden inhaltsanalytisch ausgewertet, verschlagwortet und zu Problemfeldern zusammengefasst. Abbildung 3 zeigt die so eruierten Problemfelder sowie deren quantitative Gewichtung in den untersuchten Texten innerhalb der gesetzten vier Leitdimensionen des Gentechnologieberichts. Die Abbildung illustriert dabei die Komplexität und Vernetzung der verschiedenen Diskussionsstränge, auch wenn die Darstellung immer eine Momentaufnahme bleiben muss, da Themen- und Anwendungsfelder im Bereich der

45 Für die Printmedien (a) wurde für den Zeitraum vom 01.6.2011 bis 31.05.2012 eine Volltextsuche (Stichwort: „Gendiagnostik“) in den Leitmedien SÜDDEUTSCHE ZEITUNG, FRANKFURTER ALLGEMEINE ZEITUNG DER SPIEGEL sowie DIE ZEIT durchgeführt. Für die Internetrecherche (b) wurde am 06.06.2012 via der Suchmaschine Google eine Suche nach dem Stichwort „Gendiagnostik“ zu durchgeführt; berücksichtigt wurden die ersten zehn Treffer. Mögliche Stellungnahmen (c) wurden ebenfalls online via Stichwortsuche („Gendiagnostik“ und in Verbindung mit „Stellungnahme“, aber auch „Analyse“, „Gutachten“, „Position“, „Perspektive“ bzw. „Thesen“) am 14.06.2012 via Google recherchiert; berücksichtigt wurden diejenigen Texte unter den ersten zehn Treffern, die als Stellungnahmen im engeren Sinne identifizient wurden. 
humandiagnostischen Forschung durch die enormen technischen Fortschritte in den letzten Jahren größter Dynamik unterworfen sind.

Für den Themenbereich stehen in der öffentlichen Debatte die Problemfelder Einsatz gendiagnostischer Verfahren, Rechtsrahmen, Qualitätssicherung/Arztvorbehalt im Vordergrund, die den hohen Regulierungsbedarf für die sich rasant entwickelnde humangenetische Diagnostik widerspiegeln. Ein sensibler Umgang mit genetischen Untersuchungen und den daraus generierten Daten ist für Patienten und ihre Angehörigen notwendig; berührt davon sind übergeordnete gesellschaftliche Fragen, die in Problemfeldern wie der (informellen) Selbstbestimmung, dem Datenschutz und der Missbrauchsgefahr oder auch der Gefahr der Diskriminierung aufgehen. Ein wichtiger Aspekt im Zusammenhang mit der Gendiagnostik sind auch wirtschaftliche Abwägungen, die sich mit Kosten und Nutzen der neuen technischen Möglichkeiten auseinandersetzen und sich in einer Reihe von Problemfeldern in der ökonomischen Leitdimension niederschlagen.

Abbildung 3: Erhobene Problemfelder zur Gendiagnostik in Deutschland

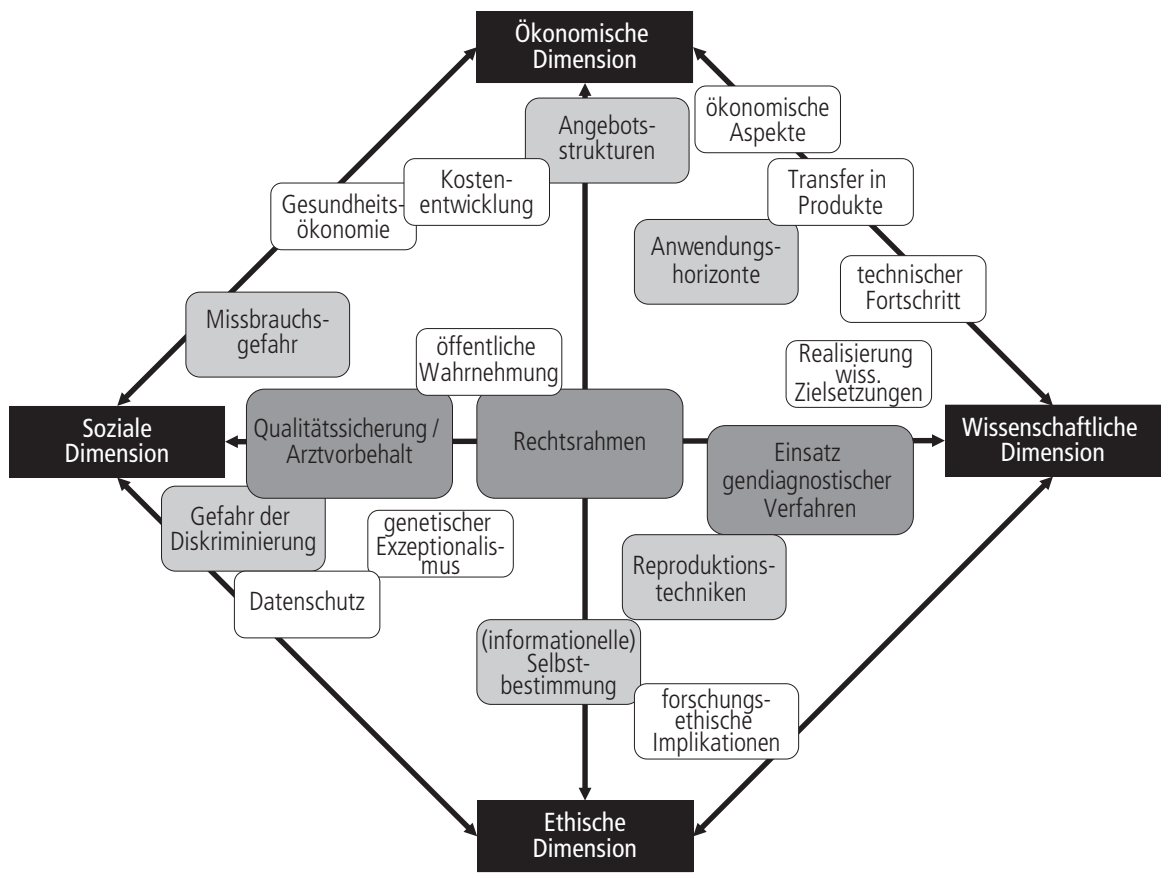


Die ermittelten Problemfelder werden in der Tabelle 1 mittels Thesen inhaltlich beschrieben und eingegrenzt. Ihre tabellarische Listung ergibt sich aus ihrer Verortung innerhalb der gesetzten Leitdimensionen (vgl. Abbildung 3). Den Problemfeldern sind in einem zweiten Schritt ausschließlich diejenigen Indikatoren zugeordnet, die sie real quantitativ ausleuchten können und die im Folgenden in standardisierten Datenblättern aufbereitet sind. Dabei ist zu beachten, dass die unterschiedlichen Problemfelder zum einen in Abhängigkeit vom zugrunde liegenden Sachverhalt unterschiedlich mit Indikatoren gefüllt werden können, zum anderen sind nicht für alle denkbaren Indikatoren für ein jeweiliges Problemfeld tatsächlich belastbare und transparente Daten zugänglich. Da die IAG primär auf externe Daten zurückgreift, kann zudem kein Einfluss auf Modus und Intervall ihrer Erhebung genommen werden - mit entsprechenden Konsequenzen für die Fortschreibung. Berücksichtigt werden allgemein also nur diejenigen Problemfelder, die sich quantitativ präzisieren lassen. Die hier nicht mit Indikatoren ausgeleuchteten Aspekte müssen qualitativ beschrieben werden und gehen, wo möglich, in den jeweiligen Texten auf.

Tabelle 1: Problemfelder zur Gendiagnostik in Deutschland und Indikatoren zu ihrer Beschreibung

\begin{tabular}{|l|l|l|}
\hline Problemfeld & These & Indikatoren \\
\hline Rechtsrahmen & $\begin{array}{l}\text { Der rechtliche Rahmen auf nationaler und euro- } \\
\text { päischer Ebene bestimmt über die Zulässigkeit von } \\
\text { gentechnischen Verfahren und definiert ihren Einsatz } \\
\text { in der wissenschaftlichen Praxis bzw. formuliert dafür } \\
\text { notwendige Rahmenbedingungen. Er hat eine Funk- } \\
\text { tion bei der Vermittlung von einander widersprechen- } \\
\text { den Interessen und Schutzgütern. }\end{array}$ & \\
\hline forschungs- \\
ethische
\end{tabular}




\begin{tabular}{|c|c|c|}
\hline Problemfeld & These & Indikatoren \\
\hline $\begin{array}{l}\text { Reproduktions- } \\
\text { techniken }\end{array}$ & $\begin{array}{l}\text { Die Gendiagnostik nimmt optional Einfluss auf die } \\
\text { menschliche Fortpflanzung. Das zeigte nicht zuletzt } \\
\text { die polarisierende Diskussion um die Präimplantati- } \\
\text { onsdiagnostik (PID) im aktuellen Berichtszeitraum. }\end{array}$ & $\begin{array}{l}\text { PID-Monitoring (GD-03) } \\
\text { Überzählige Embryonen als Folge der } \\
\text { PID (GD-09) }\end{array}$ \\
\hline \multicolumn{3}{|c|}{ Wissenschaftliche Dimension $<>$ Soziale Dimension } \\
\hline $\begin{array}{l}\text { Einsatz gen- } \\
\text { diagnostischer } \\
\text { Verfahren }\end{array}$ & $\begin{array}{l}\text { Gendiagnostische Verfahren werden für vier unter- } \\
\text { schiedliche Anwendungsgebiete genutzt: diagnos- } \\
\text { tische, präventive, vorgeburtliche, sowie Reihenun- } \\
\text { tersuchungen, die jeweils eigene gesellschaftliche } \\
\text { Folgefragen provozieren. }\end{array}$ & $\begin{array}{l}\text { Anzahl und Art der durchgeführten } \\
\text { Gentests in Deutschland (GD-02) } \\
\text { PID-Monitoring (GD-03) } \\
\text { Überzählige Embryonen als Folge der } \\
\text { PID (GD-09) } \\
\text { Entwicklung der Einträge in der } \\
\text { DNA-Analyse-Datei des BKA } \\
\text { (GD-13)* }\end{array}$ \\
\hline $\begin{array}{l}\text { Missbrauchs- } \\
\text { gefahr }\end{array}$ & $\begin{array}{l}\text { Die im Rahmen der Gendiagnostik erhobenen Daten } \\
\text { generieren ein spezifisches Wissen, das mehr als } \\
\text { das jeweilige Individuum betrifft und durch die hohe } \\
\text { Aussagekompetenz in Bezug auf Gesundheitsrisiken } \\
\text { einen sensiblen Umgang verlangt. }\end{array}$ & \\
\hline $\begin{array}{l}\text { öffentliche } \\
\text { Wahrnehmung }\end{array}$ & $\begin{array}{l}\text { Der Einsatz und die Etablierung neuer technologi- } \\
\text { scher Verfahren hängen zentral von deren gesell- } \\
\text { schaftlicher Wahrnehmung ab. Sie zeigen zudem, } \\
\text { welche Hoffnungen und Befürchtungen diesbezüglich } \\
\text { in der Bevölkerung kursieren. }\end{array}$ & $\begin{array}{l}\text { Printmediale Abbildung des } \\
\text { Themenbereichs Gendiagnostik } \\
\text { (GD-15)* } \\
\text { Neuerscheinungen zum Themen- } \\
\text { bereich Gendiagnostik (GD-16)* } \\
\text { Internetpräsenz zum Thema Gen- } \\
\text { diagnostik (GD-17)* }\end{array}$ \\
\hline $\begin{array}{l}\text { Qualitätssiche- } \\
\text { rung/Arztvor- } \\
\text { behalt }\end{array}$ & $\begin{array}{l}\text { Die Zulassung und Durchführung genetischer } \\
\text { Diagnostik muss an eine Qualitätssicherung geknüpft } \\
\text { sein. Qualitätssichernde Maßnahmen sind u.a. die } \\
\text { Einhaltung technischer Standards oder eine umfas- } \\
\text { sende Beratung. }\end{array}$ & $\begin{array}{l}\text { Akkreditierungssituation in der Human- } \\
\text { genetik (GD-10) } \\
\text { Zahl der Ringversuche (GD-11) } \\
\text { Qualitätsentwicklung in der genetischen } \\
\text { Beratung (GD-12) } \\
\text { Entwicklung der fachärztlichen } \\
\text { Versorgung im Bereich der } \\
\text { Humangenetik in Deutschland } \\
\text { (GD-14)* }\end{array}$ \\
\hline
\end{tabular}




\begin{tabular}{|c|c|c|}
\hline Problemfeld & These & Indikatoren \\
\hline $\begin{array}{l}\text { Angebotsstruk- } \\
\text { turen }\end{array}$ & $\begin{array}{l}\text { Bevor genetische Tests von verschiedenen Anbietern } \\
\text { frei am Markt zur Verfügung gestellt werden, müssen } \\
\text { deren Qualität und die Frage des etwaigen Arztvor- } \\
\text { behaltes geklärt sein. }\end{array}$ & $\begin{array}{l}\text { Anzahl der Einrichtungen, die Gen- } \\
\text { diagnostik durchführen (GD-01) } \\
\text { Entwicklung der fachärztlichen } \\
\text { Versorgung im Bereich der } \\
\text { Humangenetik in Deutschland } \\
\text { (GD-14)* }\end{array}$ \\
\hline $\begin{array}{l}\text { Anwendungs- } \\
\text { horizonte }\end{array}$ & $\begin{array}{l}\text { Anwendungshorizonte werden bereits heute } \\
\text { diskutiert, sind aber in der Praxis bislang noch nicht } \\
\text { realisiert. Sie schließen gleichfalls visionäre Ziele mit } \\
\text { hohem Innovationspotenzial ein, deren Durchführ- } \\
\text { barkeit dementsprechend ungewiss ist. Für den } \\
\text { Themenbereich Gendiagnostik gilt dies vor allem für } \\
\text { die personalisierte Medizin. }\end{array}$ & \\
\hline $\begin{array}{l}\text { ökonomische } \\
\text { Aspekte }\end{array}$ & $\begin{array}{l}\text { Der ökonomischen Verwertbarkeit von Forschungs- } \\
\text { ergebnissen wird gegenwärtig ein hoher Stellenwert } \\
\text { zugeschrieben: Für ein an Rohstoffen armes Land wie } \\
\text { Deutschland gilt eine wissensbasierte Bioökonomie } \\
\text { als zentral für den Erhalt wirtschaftlicher Prosperität } \\
\text { und internationaler Wettbewerbsfähigkeit. }\end{array}$ & $\begin{array}{l}\text { Anzahl der Einrichtungen, die Gen- } \\
\text { diagnostik durchführen (GD-01) }\end{array}$ \\
\hline $\begin{array}{l}\text { Realisierung } \\
\text { wissenschaft- } \\
\text { licher Zielset- } \\
\text { zungen }\end{array}$ & $\begin{array}{l}\text { Wissenschaftliche Forschung will neue Erkenntnisse } \\
\text { und Technologien generieren. Zu ihrem Wesen gehört } \\
\text { eine begrenzte Planbarkeit und Ergebnisoffenheit. } \\
\text { Nichtdestotrotz beeinflussen die vorhandenen } \\
\text { Rahmenbedingungen - wie die wissenschaftliche In- } \\
\text { frastruktur, Förderungsmöglichkeiten oder geltendes } \\
\text { Recht - die Realisierung von gesetzten Forschungs- } \\
\text { zielen, die sich quantifizierbar z. B. in Veröffentli- } \\
\text { chungen, Forschungspreisen oder akademischen } \\
\text { Abschlüssen niederschlagen. }\end{array}$ & $\begin{array}{l}\text { Zahl der identifizierten Gene mit Krank- } \\
\text { heitswert (GD-04) } \\
\text { Geldgeber für die Forschungsvorhaben } \\
\text { in Deutschland (GD-05) } \\
\text { Anzahl der Publikationen aus Deutsch- } \\
\text { land im Ländervergleich (GD-06) } \\
\text { Genomweite Assoziationsstudien } \\
\text { (GD-07) }\end{array}$ \\
\hline $\begin{array}{l}\text { technischer } \\
\text { Fortschritt }\end{array}$ & $\begin{array}{l}\text { Die Leistungsfähigkeit der genetischen Diagnostik } \\
\text { setzt technischen Fortschritt voraus. Dieser stellt } \\
\text { eine Grundlage für Produktentwicklungen dar und } \\
\text { beeinflusst den Einsatz bzw. die Verbreitung gendia- } \\
\text { gnostischer Verfahren. }\end{array}$ & $\begin{array}{l}\text { Entwicklung der Einträge in der } \\
\text { DNA-Analyse-Datei des BKA } \\
(\text { GD-13)* }\end{array}$ \\
\hline $\begin{array}{l}\text { Transfer in } \\
\text { Produkte }\end{array}$ & $\begin{array}{l}\text { Wissenschaft kann allgemein auch unter ökono- } \\
\text { mischen Prämissen bewertet werden. Das ist vor } \\
\text { allem dann möglich, wenn konkrete Produkte zur } \\
\text { Marktreife geführt werden. Die Etablierung der Gen- } \\
\text { diagnostik jenseits der Grundlagenforschung in die } \\
\text { klinische Praxis muss in qualitätssichernde Prozesse } \\
\text { einbezogen sein, um ihrem sensiblen Charakter zu } \\
\text { entsprechen. }\end{array}$ & $\begin{array}{l}\text { Entwicklung der Einträge in der } \\
\text { DNA-Analyse-Datei des BKA } \\
(\text { GD-13)* }\end{array}$ \\
\hline
\end{tabular}




\begin{tabular}{|c|c|c|}
\hline Problemfeld & These & Indikatoren \\
\hline Datenschutz & $\begin{array}{l}\text { Die Erhebung und Speicherung genetischer Daten } \\
\text { ermöglicht prinzipiell eine weitergehende Nutzung, } \\
\text { die möglicherweise individuelle Rechte tangiert. }\end{array}$ & \\
\hline $\begin{array}{l}\text { Gefahr der Dis- } \\
\text { kriminierung }\end{array}$ & $\begin{array}{l}\text { Personen mit bestimmten genetischen Dispositionen } \\
\text { könnten u.a. im Arbeits- und Versicherungsbereich } \\
\text { diskriminiert werden. Durch die Möglichkeiten der } \\
\text { vorgeburtlichen Diagnostik können zudem Aussagen } \\
\text { über die jeweilige genetische Disposition getroffen } \\
\text { werden. Auch hier besteht die Gefahr der Wertung. }\end{array}$ & \\
\hline $\begin{array}{l}\text { genetischer Ex- } \\
\text { zeptionalismus }\end{array}$ & $\begin{array}{l}\text { Hierbei ist die Frage zentral, ob und wenn ja in } \\
\text { welchem Sinne genetischen Daten im Vergleich } \\
\text { zu anderen medizinischen Daten ein Sonderstatus } \\
\text { zukommt. }\end{array}$ & \\
\hline $\begin{array}{l}\text { (informationelle) } \\
\text { Selbstbestim- } \\
\text { mung }\end{array}$ & $\begin{array}{l}\text { Die Idee des „informed consent" gilt als Basis jedes } \\
\text { diagnostischen oder therapeutischen Eingriffs. Das } \\
\text { Recht auf informationelle Selbstbestimmung Dritter } \\
\text { kann ggf. mit der Erhebung, Speicherung und Weiter- } \\
\text { gabe genetischer Daten kollidieren. }\end{array}$ & Beratungsangebote (GD-08) \\
\hline \multicolumn{3}{|c|}{ Soziale Dimension <>Ökonomische Dimension } \\
\hline $\begin{array}{l}\text { Gesundheits- } \\
\text { ökonomie }\end{array}$ & $\begin{array}{l}\text { Bei wachsenden diagnostischen Möglichkeiten ist zu } \\
\text { prüfen, in welchem Kosten-Nutzen-Verhältnis präven- } \\
\text { tive und therapeutische Verfahren stehen. }\end{array}$ & \\
\hline $\begin{array}{l}\text { Kostenentwick- } \\
\text { lung }\end{array}$ & $\begin{array}{l}\text { Infolge einer routinemäßigen Anwendung gendia- } \\
\text { gnostischer Verfahren könnte sich die Frage nach den } \\
\text { finanziellen Konsequenzen für die Solidargemein- } \\
\text { schaft stellen. }\end{array}$ & \\
\hline
\end{tabular}

Die fett markierten Indikatoren werden nachfolgend anhand detaillierter Datenblätter vorgestellt und grafisch aufbereitet; * kennzeichnet neue Indikatoren im Vergleich zur letzten Veröffentlichung der Daten (vgl. Müller-Röber et al., 2009:132-163).

Die Gendiagnostik wird seit Bestehen der Arbeitsgruppe beobachtet, 2005 wurden erstmals in diesem Sinne standardisierte Indikatorenblätter veröffentlicht. Dies war auch im Themenband „Gendiagnostik in Deutschland“ (Domasch; Boysen; Pabst, Schmidtke, 2007:179-204), sowie im „Zweiten Gentechnologiebericht“ (Müller-Röber et al., 2009:132-167). Für vorliegenden „Dritten Gentechnologiebericht“ wurden das Datenmaterial grundlegend überarbeitet, neu strukturiert - es wurde beispielsweise der ehemalige Indikator GD-09 in den Indikator GD_03 aufgrund der derselben Datenbasis integriert -, und so der hohen Dynamik des Themenbereichs angepasst. Alle bereits vorhandenen Indikatoren wurden kritisch auf Fortschreibung geprüft, teilweise auch ausgesetzt und liegen in neu aufbereitetem Format vor. Letzteres ist auch der Idee geschuldet, die unterschiedlichen Themenbereiche miteinander vergleichbar zu machen. 
Im Zuge dessen konnten etwa drei neue Indikatoren gewonnen werden (GD-15, GD-16, GD-17). Die Rubriken „Abgrenzung der Berechnungsgrößen“ und „Aussagefähigkeit“ bilden dabei, wie auch bei den anderen Themen dieses Bandes, den interpretativen Rahmen. 
Laufende Nr:: GD-01

Problemfeld: Angebotsstrukturen + ökonomische Aspekte

\section{INDIKATOR: ANZAHL DER EINRICHTUNGEN, DIE GENDIAGNOSTIK DURCHFÜHREN}

\section{DATENQUELLE:}

Hucho, F. et al. (2005): Gentechnologiebericht. Analyse einer Hochtechnologie in Deutschland. München:201f. (für 1998 bis 2005; die Daten stützen sich auf die Vorgänger-Datenbank QMD-BVDH); Müller-Röber, B. et. al (2009):

Zweiter Gentechnologiebericht. Analyse einer Hochtechnologie in Deutschland. Dornburg:141f. (für 2008)

Datenbank des Humangenetischen Qualitätsnetzwerkes, unter dem Dach des Bundesverbandes deutscher Humangenetiker e.V. Unter: www.hgqn.org/ (für 2013)

Zugriff: September 2014 Stand: September 2014

\section{VERFÜGBARKEIT DER DATEN:}

öffentlich

„Das Human Genetic Quality Network (HGQN) ist eine Plattform für alle humangenetischen Einrichtungen in Deutschland, Österreich und der Schweiz, sich selbst darzustellen, das Spektrum ihrer Diagnostikleistungen zu zeigen, ihre Beteiligung an qualitätssichernden Maßnahmen zu dokumentieren und Ansprechpartner in folgenden Bereichen zu nennen: Molekulargenetik, Zytogenetik, molekularer Zytogenetik, Tumorgenetik und Genetischer Beratung" (http:// www.hggn.org/de/help/ [04.12.2013]). Die in die Datenbank aufgenommenen Einrichtungen unterlaufen dabei einem Gutachterverfahren.

\section{ABGRENZUNG DER BERECHNUNGSGRÖSSEN:}

Die Angaben des Indikators beziehen sich auf den gesamten deutschsprachigen Raum (Deutschland, Österreich, Schweiz). Zur Ermittlung der Daten wurde die Kategorisierung nach "Genetische Beratung" ausgeführt. In welchem Fachgebiet die genetische Beratung stattfindet, ist nicht differenziert. Einrichtungen aus dem nichtdeutschsprachigen Raum wurden aus der Betrachtung ausgeschlossen.

\section{GLIEDERUNG DER DARSTELLUNG:}

Anzahl der Einrichtungen, die Gentests durchführen

\section{BERECHNUNGSHÄUFIGKEIT:}

fortlaufend

\section{AUSSAGEFÄHIGKEIT:}

Die Zahl der Einrichtungen, die genetische Tests durchführen, sagt unmittelbar etwas über die Angebotsstrukturen im deutschsprachigen Raum aus. 
a) Abbildung 4: Anzahl der Einrichtungen, die Gentests durchführen

180

150

120

90

60

30

0
112

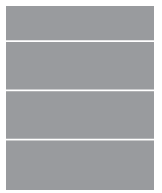

2005
169

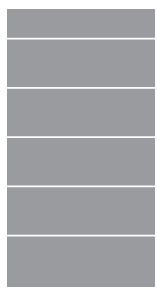

2008
114

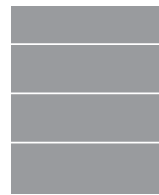

$2014^{*}$

* Stand 15.09.2014. Die angegeben Daten orientieren sich am Publikationsjahr der vorangegangen Gentechnologieberichte. Es werden ausschließlich Einrichtungen betrachtet, in denen genetische Testverfahren zur Anwendung kommen. Einrichtungen, die lediglich Beratungsleistungen anbieten, werden aus der Betrachtung ausgeschlossen.

Quelle: siehe Indikatorenblatt GD-01. 
Laufende Nr:: GD-02

Problemfeld: Einsatz gendiagnostischer Verfahren

\section{INDIKATOR: ANZAHL UND ART DER DURCHGEFÜHRTEN GENTESTS IN DEUTSCHLAND}

\section{ANMERKUNG:}

Der Indikator wurde zuletzt in Müller-Röber et al. (2009:142) veröffentlicht. Er stellte eine einmalige Erhebung dar und listete genetisch bedingte Krankheiten mit Erkrankungsrisiko, Beginn der klinischen Manifestation und dem Alter bei prädiktiver Testung modifiziert nach Propping et al. (2006). Die Daten sind im ursprünglichen Format nicht fortschreibbar; entsprechende Recherchen für alternative Quellen werden permanent weitergeführt. 
Laufende Nr:: GD-03

Problemfeld: Reproduktionstechniken + Einsatz gendiagnostischer Verfahren

\section{INDIKATOR: PID-MONITORING}

\section{DATENQUELLE:}

ESHRE PGD Consortium Data Collection (I bis XII) veröffentlicht im Journal „Human Reproduction“. Unter:

http://humrep.oxfordjournals.org/

Zugriff: September 2014, Stand: März 2014 (für Daten bis Dezember 2009).

\section{VERFÜGBARKEIT DER DATEN:}

\section{öffentlich}

Das Preimplantation Genetic Diagnosis (PGD) Consortium wurde 1997 von der European Society of Human Reproduction and Embryology (ESHRE) mit dem Ziel gegründet ein umfassendes Monitoring der unterschiedlichen Methoden der Präimplantationsdiagnostik (PID) sicherzustellen. Dies soll durch die umfassende Sammlung prospektiver und retrospektiver Daten zur Genauigkeit, Reliabilität, Effektivität und Sicherheit der PID gewährleistet werden Zum Zeitpunkt der letzten Veröffentlichung 2014 beteiligten sich 60 internationale Präimplantationsdiagnostik-Zentren, die ihre Daten über eine FileMaker Pro-Datenbank, in anonymisierter Form, an das PGD Consortium übermittelten. Die Daten werden in regelmäßigen Abständen gesammelt auf den sog. „ESHRE PAGES" des medizinwisschenschafltichen Journals „Human Reproduction" veröffentlicht (http://humrep.oxfordjournals.org/content/early/2014/03/11/humrep.deu012.full.pdf [23.09.2014]).

\section{ABGRENZUNG DER BERECHNUNGSGRÖSSEN:}

Die Zahlen sind jeweils auf den genannten Berichtszeitraum bezogen (nicht kumulativ) und umfassen sämtliche Ausprägungen der Präimplantationsdiagnostik (PID) (u. a. PID zur Feststellung von monogen bedingten Krankheiten, Chromosomenanomalien, numerischen Chromosomenaberrationen (Aneuploidie) sowie zur Durchführung von "Social Sexing" und Sexing nach X-chromosomal vererbbaren Krankheiten.

\section{GLIEDERUNG DER DARSTELLUNG:}

Ergebnisse der in Europa durchgeführten PID

\section{BERECHNUNGSHÄUFIGKEIT:}

In den angegebenen Zeiträumen, prinzipiell jährlich

\section{AUSSAGEFÄHIGKEIT:}

Dieser Indikator gibt Auskunft darüber, inwieweit auf internationaler Ebene Eizellen entnommen werden, an denen möglicherweise gendiagnostische Verfahren im Rahmen einer PID zum Einsatz kommen. Das PGD Consortium dokumentiert weiterhin die Anzahl der diagnostizierten und als transferierbar eingestuften Embryonen. Die nicht transferierten Embryonen werden in der Regel eingefroren, um für spätere Behandlungen zur Verfügung zu stehen. Wird dies von den Eltern nicht mehr gewünscht, ergibt sich ein großer "Vorrat” an „"̈̈berzähligen" Embryonen. Die an das PGD Consortium übermittelten Daten lassen generell keinen Rückschluss auf die Entwicklung der PID in ausgewählten Ländern zu, da die Übermittlung der Daten auf freiwilliger Basis beruht und in anonymisierter Form stattfindet, mithin eine Zuordnung zu einzelnen Zentren nicht möglich ist. 
Tabelle 2: Ausgewählte Daten zur PID aus den Berichten des ESHRE PGD Consortiums

\begin{tabular}{|c|c|c|c|c|c|c|}
\hline & ESHRE I & ESHRE II & ESHRE III & ESHRE IV & ESHRE V & ESHRE VI \\
\hline Jahr & 1999* & $2000^{*}$ & 2002 & 2005 & 2006 & 2007 \\
\hline \multirow[t]{2}{*}{ Erhobener Zeitraum } & $\begin{array}{l}01 / 1997 \text { - } \\
09 / 1998\end{array}$ & $\begin{array}{l}10 / 1998- \\
04 / 2000\end{array}$ & $\begin{array}{l}05 / 2000- \\
04 / 2001\end{array}$ & $\begin{array}{l}05 / 2001 \text { - } \\
12 / 2001\end{array}$ & $\begin{array}{l}01 / 2002- \\
12 / 2002\end{array}$ & $\begin{array}{l}01 / 2003- \\
12 / 2003\end{array}$ \\
\hline & 21 Monate & 19 Monate & 12 Monate & 8 Monate & 12 Monate & 12 Monate \\
\hline Anzahl beteiligter Zentren & 16 & 26 & $\begin{array}{l}\text { keine } \\
\text { Angabe }\end{array}$ & 36 & 43 & 50 \\
\hline Anzahl gewonnener Eizellen 1) & $\begin{array}{l}\text { keine } \\
\text { Angabe }\end{array}$ & 16.292 & $\begin{array}{l}\text { keine } \\
\text { Angabe }\end{array}$ & 23.976 & 26.747 & 36.376 \\
\hline Anzahl inseminierter Eizellen & 4.473 & 14.522 & 10.298 & 19.869 & 22.383 & 30.088 \\
\hline $\begin{array}{l}\text { Anzahl erfolgreich biopsierter } \\
\text { Embryonen }\end{array}$ & 2.330 & 7.991 & 5.698 & 9.918 & 12.158 & 16.030 \\
\hline $\begin{array}{l}\text { Anzahl diagnostizierter } \\
\text { Embryonen }\end{array}$ & 2.086 & 6.182 & 5.057 & 9.036 & 11.069 & 14.747 \\
\hline $\begin{array}{l}\text { Anzahl transferierbarer } \\
\text { Embryonen }\end{array}$ & 919 & 2.514 & 2.084 & 3.438 & 4.105 & 5.371 \\
\hline $\begin{array}{l}\text { Anzahl transferierter Em- } \\
\text { bryonen }\end{array}$ & 659 & 2.248 & 1.409 & 2.555 & 2.842 & 3.695 \\
\hline $\begin{array}{l}\text { Anzahl eingefrorener Em- } \\
\text { bryonen }\end{array}$ & 137 & 367 & 325 & 290 & 432 & 714 \\
\hline $\begin{array}{l}\text { Anzahl klinischer Schwanger- } \\
\text { schaften }{ }^{2)}\end{array}$ & 67 & 274 & 175 & 298 & 365 & 511 \\
\hline
\end{tabular}


Tabelle 2: Fortsetzung

\begin{tabular}{|c|c|c|c|c|c|c|}
\hline & ESHRE VII & ESHRE VIII & ESHRE IX & ESHRE X & ESHRE XI & ESHRE XII \\
\hline Jahr & 2008_1 & 2008_2 & 2009 & 2010 & 2012 & 2014 \\
\hline \multirow[t]{2}{*}{ Erhobener Zeitraum } & $\begin{array}{l}01 / 2004- \\
12 / 2004\end{array}$ & $\begin{array}{l}01 / 2005- \\
12 / 2005\end{array}$ & $\begin{array}{l}01 / 2006- \\
12 / 2006\end{array}$ & $\begin{array}{l}01 / 2007- \\
12 / 2007\end{array}$ & $\begin{array}{l}01 / 2008- \\
12 / 2008\end{array}$ & $\begin{array}{l}01 / 2009- \\
12 / 2009\end{array}$ \\
\hline & 12 Monate & 12 Monate & 12 Monate & 12 Monate & 12 Monate & 12 Monate \\
\hline Anzahl beteiligter Zentren & 45 & 39 & 57 & 57 & 53 & 60 \\
\hline Anzahl gewonnener Eizellen 1) & 41.964 & 42.778 & 69.473 & 68.568 & 65.909 & 72.894 \\
\hline Anzahl inseminierter Eizellen & 34.397 & 35.184 & 58.388 & 56.325 & 55.340 & 60.372 \\
\hline $\begin{array}{l}\text { Anzahl erfolgreich biopsierter } \\
\text { Embryonen }\end{array}$ & 19.430 & 19.600 & 31.731 & 31.520 & 30.264 & 35.049 \\
\hline $\begin{array}{l}\text { Anzahl diagnostizierter } \\
\text { Embryonen }\end{array}$ & 18.096 & 18.451 & 29.337 & 28.998 & 28.349 & 32.682 \\
\hline $\begin{array}{l}\text { Anzahl transferierbarer } \\
\text { Embryonen }\end{array}$ & 6.642 & 6.580 & 10.580 & 10.084 & 9.900 & 11.644 \\
\hline $\begin{array}{l}\text { Anzahl transferierter Em- } \\
\text { bryonen }\end{array}$ & 4.248 & 4.246 & 7.283 & 7.183 & 6.665 & 7.618 \\
\hline $\begin{array}{l}\text { Anzahl eingefrorener Em- } \\
\text { bryonen }\end{array}$ & 893 & 980 & 1.568 & 1.386 & 1.654 & 1.967 \\
\hline $\begin{array}{l}\text { Anzahl klinischer Schwanger- } \\
\text { schaften }{ }^{2)}\end{array}$ & 604 & 663 & 1.210 & 1.276 & 1.200 & 1.417 \\
\hline
\end{tabular}

Berücksichtigt werden alle Ausprägungen der Präimplantationsdiagnostig (PID), welche in den Berichten unter den Begriffen „Preimplantation Genetic Diagnosis" (PGD), "Preimplantation Genetic Screeing" (PGS) und "Preimplantation Genetic Diagnosis for Social Sexing" (PGD-SS) subsumiert sind. * In den ersten zwei Berichten wurden von den beteiligten Zentren keine Daten zum "Social Sexing" übermittelt. Ab dem dritten Bericht wurden entsprechende Daten erstmalig übermittelt und seit dem Aufgeführt. ${ }^{1)}$ COCs, cumulus-ooctye complex. ${ }^{2)}$ "Positive Heart Beat"; 2012 "Positive FHB".

Quelle: siehe Indikatorenblatt GD-03. 
Laufende Nr.: GD-04, GD-05, GD-06

Problemfeld: Realisierung wissenschaftlicher Zielsetzungen

\section{INDIKATOR: ZAHL DER IDENTIFIZIERTEN GENE MIT KRANKHEITSWERT (GD-04)} GELDGEBER VON AUTORINNEN UND AUTOREN IN DEUTSCHLAND (GD-05) ANZAHL DER PUBLIKATIONEN AUS DEUTSCHLAND IM LÄNDERVERGLEICH (GD-06)

\section{ANMERKUNG:}

Die benannten Indikatoren wurde zuletzt in Müller-Röber et al. (2009:145ff) veröffentlicht. Als Grundlage der Recherche wurde die OMIM-Datenbank (Online Mendelian Inheritance in Man, www.omim.org/ [22.09.2014] ) genutzt. Sie führten Veröffentlichungen auf, die Gene für monogen bedingte Krankheiten (erstmalig) identifizieren - in Korrelation zu Erstautorschaften aus Deutschland (GD-04), den Förderinstitutionen für die zugrunde liegenden Studien mit deutscher Erstautorschaft (GD-05) sowie ein genereller Vergleich an Erstautorschafen für ausgewählte Länder (GD-06). Die Indikatoren sind im ursprünglichen Format für die Arbeitsgruppe nicht mehr fortschreibbar: Die Liste von Genen, deren Defekte zu ernsten (monogen bedingten) Krankheiten führen, ist mittlerweile viel zu lang, und sie wird jeden Tag länger. Zurzeit enthält sie bereits mehr als 4000 Gene. Mithilfe genomischer Sequenzierungen lassen heute sich im Prinzip sämtliche dieser Defekte erfassen, ihr eigentlicher Krankheitswert ist erst durch weiterführende Untersuchungen nachzuweisen. 
Laufende Nr:: GD-07

Problemfeld: Realisierung wissenschaftlicher Zielsetzungen

\section{INDIKATOR: GENOMWEITE ASSOZIATIONSSTUDIEN}

\section{DATENQUELLE:}

The NHGRI GWAS Catalog. Unter: www.genome.gov/gwastudies

PubMed Online-Literaturdatenbank. Unter: www.ncbi.nlm.nih.gov/pubmed

Zugriff: Oktober 2014, Stand: Oktober 2014.

\section{VERFÜGBARKEIT DER DATEN:}

\section{öffentlich}

Das US-amerikanische National Human Genome Research Institute (NHGRI) stellt kostenlos den sogenannten Catalog of Published Genome-Wide Association Studies (GWAS) zur Verfügung. Diese von Sachverständigen gepflegte OnlineRessource stellt Daten aus veröffentlichten genomweiten Assoziationsstudien zusammen, die festgelegte Mindeststandards erfüllen (Screening von min. 100.000 Einzelnukleotid-Polymorphismen, Signifikanzschwelle von $p<1.0 \times 10^{-5}$ ); für die Literatursuche wird auf die Online-Datenbank PubMed zurückgegriffen, die aktuelle biomedizinische Fachliteratur listet. Zum Recherchezeitpunkt am 10.01.2014 führte der GWAS-Katalog 1963 Veröffentlichungen und 14017 SNPs an.

\section{ABGRENZUNG DER BERECHNUNGSGRÖSSEN:}

Der Indikator korrelliert die Einträge in der GWAS-Datenbank mit den hinter ihnen liegenden Veröffentlichungen. Es wurden alle am Stichtag im Katalog aufgeführten Studien berücksichtigt und keine weiterführende Filterung der Daten durchgeführt. Die Jahrsangabe bezieht sich - wo vorhanden - auf die Online-Veröffentlichung (Epub). Es wurden zusätzlich diejenigen Veröffentlichungen recherchiert, für die eine Erstautorschaft aus Deutschland in PubMed angegeben ist. Auf die händische Aufschlüsselung aller Erstautorschaften wurden im Gegensatz zur vorangegangen Veröffentlichung (vgl. Müller-Röber et al., 2009:150f.) aufgrund des starken Anstiegs an Studien insgesamt sowie der Zunahme an kollaborativen Studien ohne eindeutige Hauptautorschaft verzichtet.

\section{GLIEDERUNG DER DARSTELLUNG:}

Jährlich veröffentlichte genomweite Assoziationsstudien (GWAS)

\section{BERECHNUNGSHÄUFIGKEIT:}

jährlich

\section{AUSSAGEFÄHIGKEIT:}

Seit 2007 wurden verstärkt genomweite Assoziationsstudien durchgeführt - verknüpft mit großen Hoffnungen für die Biomedizin. Diese Studien typisieren sogenannte Einzelnukleotid-Polymorphismen (SNPs) und analysieren statistisch signifikante Unterschiede zwischen den DNA-Sequenzen von gesunden und erkrankten Personengruppen. Ziel war und ist ein besseres Verständnis der Risikofaktoren und der molekularen Pathogenese gerade häufiger Erkrankungen, die im Gegensatz zu den seltenen monogenen Erkrankungen nicht auf einen einzelnen Gendefekt zurückführbar sind. Vielmehr beruhen diese "multifaktoriellen“ Erkrankungen - wie zum Beispiel Diabetes oder auch Autoimmunkrankheiten auf einem komplexen Wechselspiel genetischer und nicht-genetischer Faktoren, das für die meisten dieser Krankheiten bisher nur unzureichend verstanden ist. Genomweite Assoziationsstudien haben eine Fülle an wissenschaftlichen Daten geliefert; allerdings haben sie bisher nur in wenigen Fällen grundlegend neue Erkenntnisse befördert. Auch Hoffnungen für ihre klinische Applikation haben sich bisher nicht erfüllt: Die meisten identifizierten SNPs erhöhen das jeweilige Krankheitsrisiko nur geringfügig und eignen sich so nicht als diagnostische oder prognostische Marker. Inwiefern die Typisierung von SNPs in Kombination mit anderen Ansätzen (z. B. epigenetischen Daten) ertragreicher für das Verständnis und die Behandlung von komplexen multifaktoriellen Erkrankungen ist, wird sich erst zukünftig zeigen. 
Abbildung 5: Jährlich veröffentlichte genomweite Assoziationsstudien (GWAS)

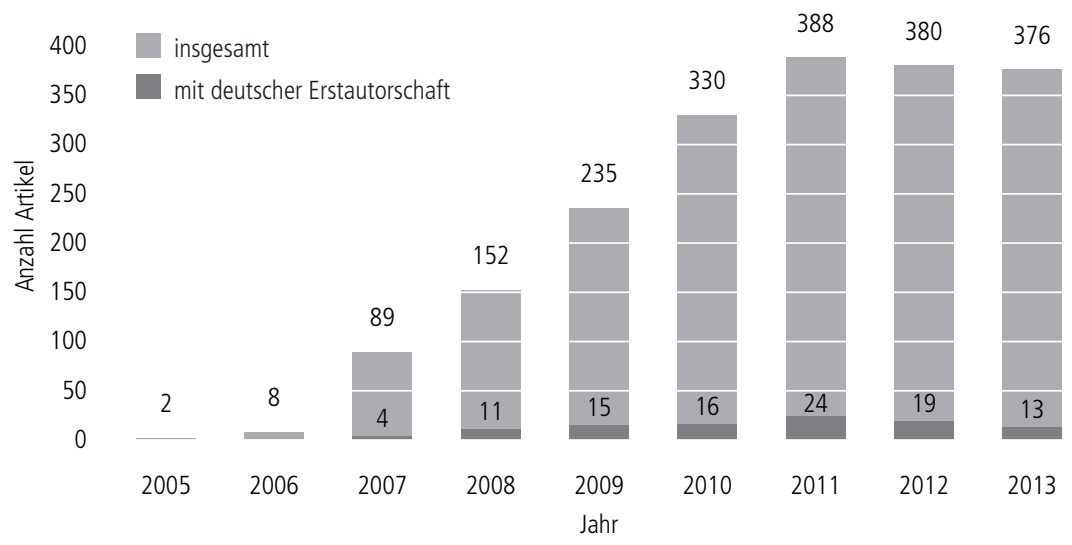

Jeweils aktualisierte Daten. Abweichungen zu früheren Veröffentlichungen möglich.

Quelle: siehe Indikatorenblatt GD-07. 
Laufende Nr.: GD-08

Problemfeld: Informationelle Selbstbestimmung

\section{INDIKATOR: BERATUNGSANGEBOTE}

\section{ANMERKUNG:}

Der Indikator wurde zuletzt in Müller-Röber et al. (2009:152f) veröffentlicht. Er stellte eine einmalige Erhebung dar und listete die Erwartungshaltung sowie die Zufriedenheit von Patientinnen und Patienten im Hinblick auf die genetische Beratungsleistung modifiziert nach Vlasak/Amann (2006). Die Daten sind im ursprünglichen Format nicht fortschreibbar; entsprechende Recherchen auch bei anderen Quellen werden permanent weitergeführt.

Laufende Nr:: GD-09

Problemfeld: Reproduktionstechniken

\section{INDIKATOR: ÜBERZÄHLIGE EMBRYONEN ALS FOLGE DER PID (IN EUROPA)}

\section{ANMERKUNG:}

Der Indikator wurde zuletzt in Müller-Röber et al. (2009:154) veröffentlicht. Er stellte eine Auflistung überzähliger Embryonen als Folge der Präimplantationsdiagnostik (PID) dar. Die Informationen dieses Indikators gehen in GD-03 auf.

Laufende Nr.: GD-10

Problemfeld: Qualitätssicherung/Arztvorbehalt

\section{INDIKATOR: AKKREDITIERUNGSITUATION IN DER HUMANGENETIK}

\section{ANMERKUNG:}

Der Indikator wurde erstmalig in Müller-Röber et al. (2009:155f.) veröffentlicht. Er listete eine einmalige Erhebung diverser Kennzahlen für medizinische Laboratorien in Deutschland und ausgewählten europäischen Ländern, die nach den damals gültigen Richtlinien akkreditiert waren. Als Datenquellen (ebd.) wurden Akkreditierungsstellen genutzt, die seit 2010 nunmehr über die Deutsche Akkreditierungsstelle (DAkkS) gebündelt werden, die gegenwärtig als alleiniger Dienstleister für Akkreditierung in Deutschland tätig ist. Entsprechend kann die damals gewählte Darstellung nicht fortgeschrieben werden; es kann nur eine Momentaufnahme der gegenwärtigen Akkreditisierungssituation der medizinischen Labore in Deutschland gegeben werden: Gegenwärtig verzeichnet das Online-Verzeichnis der DAkkS (http:// www.dakks.de/content/verzeichnisse-akkreditierter-stellen) insgesamt 424 medizinische Labore nach ISO/IEC 15189 in Deutschland (Stand 2009: 374), darunter 180 (Stand 2009: 113) für das Untersuchungsgebiet Humangenetik, das sowohl medizinische Labore für molekulare Humangenetik, aber auch Tumorzytogenetik und allgemeine Zytogenetik erfasst. Wie schon im letzten Bericht ausgeführt, gilt es im sensiblen Bereich der humangenetischen Diagnostik Qualitätsstandards zu sichern und beständig weiterzuentwickeln, die aktuellen Entwicklungen gerade in diesem Bereich schlagen sich noch nicht aussagekräftig in den zur Verfügung stehenden Daten nieder. Erst ein längerfristiges Monitoring wird hier Tendenzen abbilden. 
Laufende Nr.: GD-11

Problemfeld: Qualitätssicherung/Arztvorbehalt

\section{INDIKATOR: ZAHL DER RINGVERSUCHE}

\section{DATENQUELLE:}

Human Genetic Quality Network (HGQN). Unter: www.hgqn.org

Zugriff: Dezember 2013, Stand: k. A.

\section{VERFÜGBARKEIT DER DATEN:}

öffentlich

\section{ABGRENZUNG DER BERECHNUNGSGRÖSSEN:}

Für die Recherche wurden die auf der Website vermerkten „Ringversuche“ nach Jahren erfasst. Es wurden dabei sowohl die Versuche a) insgesamt (Auswahl "alle" im Dropdown-Menü unter Organisation und Kategorisierungen) wie auch aufgeschlüsselt nach den jeweils einzeln aufgeführten b) Organisationen und c) Kategorisierungen. Die Darstellung wurde im vorliegenden Bericht in Anpassung an die zunehmende Datenmenge modifiziert. Auf die Darstellung der Zahl der teilnehmenden Institutionen wurde verzichtet, da zunehmend keine entsprechenden Angaben mehr zur Verfügung stehen.

\section{GLIEDERUNG DER DARSTELLUNG:}
a) Anzahl an Ringversuchen insgesamt
b) Anzahl an Ringversuchen aufgeschlüsselt nach durchführender Organisation
c) Anzahl an Ringversuchen aufgeschlüsselt nach Kategorien

\section{BERECHNUNGSHÄUFIGKEIT:}

fortlaufend

\section{AUSSAGEFÄHIGKEIT:}

Ein Ringversuch ist eine Methode der externen Qualitätssicherung; dabei werden identische Proben in verschiedenen Laboren untersucht. Die Initiierung von Ringversuchen ist ein notwendiger Schritt hinsichtlich der Standardisierung von Messverfahren und der Reduzierung von technischen Fehlerquoten vor dem Hintergrund der Qualitätssicherung genetischer Tests. 
a) Abbildung 6: Anzahl an Ringversuchen insgesamt

160

140

120

100

80

60

44

40
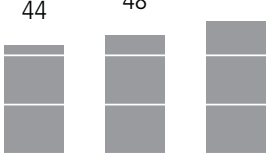

66

2003

$2004 \quad 2005$

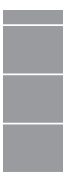

63

*Stand: Dezember 2013. Noch laufende Versuche wurden nicht berücksichtigt. Quelle: siehe Indikatorenblatt GD-11.

b) Tabelle 3: Anzahl an Ringversuchen aufgeschlüsselt nach durchführender Organisation

\begin{tabular}{|l|c|c|c|c|c|c|c|c|c|c|c|}
\hline & $\mathbf{2 0 0 3}$ & $\mathbf{2 0 0 4}$ & $\mathbf{2 0 0 5}$ & $\mathbf{2 0 0 6}$ & $\mathbf{2 0 0 7}$ & $\mathbf{2 0 0 8}$ & $\mathbf{2 0 0 9}$ & $\mathbf{2 0 1 0}$ & $\mathbf{2 0 1 1}$ & $\mathbf{2 0 1 2}$ & $\mathbf{2 0 1 3}^{*}$ \\
\hline DGKL & 17 & 18 & 21 & 25 & 19 & 27 & 25 & 12 & 0 & 0 & 0 \\
\hline BVDH & 17 & 15 & 17 & 18 & 16 & 5 & 3 & 3 & 5 & 5 & 7 \\
\hline INSTAND & 9 & 10 & 10 & 13 & 17 & 17 & 34 & 52 & 40 & 21 & 46 \\
\hline EMQN & 0 & 3 & 4 & 1 & 2 & 34 & 30 & 42 & 23 & 1 & 1 \\
\hline $\begin{array}{l}\text { CF European } \\
\text { Network }\end{array}$ & 1 & 2 & 2 & 1 & 1 & 2 & 1 & 3 & 2 & 0 & 0 \\
\hline CAP & 0 & 0 & 0 & 8 & 7 & 8 & 8 & 9 & 4 & 5 & 7 \\
\hline RfB & & & & & & & 13 & 21 & 64 & 37 & 11 \\
\hline ÖGH / SGMG** & 0 & 0 & 0 & 0 & 0 & 1 & 0 & 0 & 0 & 0 & 0 \\
\hline keine Angabe & & & & & 1 & & 2 & & 2 & 2 & 1 \\
\hline
\end{tabular}

*Stand: Dezember 2013. Noch laufende Versuche wurden nicht berücksichtigt. DGKL = Deutsche Vereinte Gesellschaft für Klinische Chemie und Laboratoriumsmedizin e.V.; BVDH = Berufsverband Deutscher Humangenetiker e.V.; INSTAND = Institut für Standardisierung und Dokumentation im medizinischen Laboratorium e.V.; EMQN = European Molecular Genetics Quality Network; CF European Network = Cystic Fibrosis European Network; CAP = Collage of American Pathologists; RfB = Referenzinstitut für Bioanalytik; ÖGH / SGMG = Österreichische Gesellschaft für Humangenetik / Schweizerische Gesellschaft für Medizinische Genetik. ${ }^{*}$ In Kooperation mit BVDH. 
c) Tabelle 4: Anzahl an Ringversuchen aufgeschlüsselt nach Kategorien

\begin{tabular}{|l|c|c|c|c|c|c|c|c|c|c|c|}
\hline & $\mathbf{2 0 0 3}$ & $\mathbf{2 0 0 4}$ & $\mathbf{2 0 0 5}$ & $\mathbf{2 0 0 6}$ & $\mathbf{2 0 0 7}$ & $\mathbf{2 0 0 8}$ & $\mathbf{2 0 0 9}$ & $\mathbf{2 0 1 0}$ & $\mathbf{2 0 1 1}$ & $\mathbf{2 0 1 2}$ & $\mathbf{2 0 1 3}^{*}$ \\
\hline $\begin{array}{l}\text { molekular- } \\
\text { genetisch }\end{array}$ & 39 & 44 & 48 & 61 & 58 & 90 & 110 & 135 & 131 & 65 & 67 \\
\hline zytogenetisch & 4 & 1 & 5 & 3 & 4 & 3 & 4 & 3 & 3 & 0 & 6 \\
\hline $\begin{array}{l}\text { molekular } \\
\text { zytogenetisch }\end{array}$ & 1 & 2 & 0 & 1 & 0 & 1 & 0 & 0 & 0 & 2 & 0 \\
\hline $\begin{array}{l}\text { tumorzyto- } \\
\text { genetich }\end{array}$ & 0 & 0 & 0 & 0 & 0 & 0 & 0 & 0 & 1 & 1 & 0 \\
\hline $\begin{array}{l}\text { methodisch- } \\
\text { technisch }\end{array}$ & 0 & 0 & 1 & 0 & 0 & 26 & 11 & 3 & 0 & 0 & 0 \\
\hline keine Angabe & 0 & 1 & 0 & 2 & 1 & 0 & 0 & 1 & 5 & 3 & 0 \\
\hline
\end{tabular}

*Stand: Dezember 2013. Noch laufende Versuche wurden nicht berücksichtigt. Teilweise wurde eine Mehrfachkategorisierung vorgenommen, dies ist in der Abbildung kumuliert.

Quelle: siehe Indikatorenblatt GD-11. 
Laufende Nr.: GD-12

Problemfeld: Qualitätssicherung/Arztvorbehalt

\section{INDIKATOR: QUALITÄTSICHERUNG IN DER GENETISCHEN BERATUNG}

\section{ANMERKUNG:}

Der Indikator wurde zuletzt in Müller-Röber et al. (2009:162f.) veröffentlicht. Er stellte eine einmalige Erhebung dar und listete diverse Kennzahlen zur genetischen Beratung, die einer Umfrage des Berufsverbandes Deutscher Humangenetiker e. V. entnommen wurden. Die Daten sind im ursprünglichen Format nicht fortschreibbar; entsprechende Recherchen auch bei anderen Quellen werden permanent weitergeführt. Seit 2009 regelt zudem das Gendiagnostikgesetz die Rahmenbedingungen der genetischen Beratung. 2011 wurde die "Richtlinie der Gendiagnostik-Kommission (GEKO) über die Anforderung an die Qualifikation zur und Inhalte der genetische Beratung gemäß §23 Abs. 2a und § 23 Abs. $2 \mathrm{Nr} .3$ GenDG" erlassen, die spezifische Vorgehensweisen konkretisiert. 
Laufende Nr.: GD-13

Problemfeld: Technischer Fortschritt + Transfer in Produkte + Einsatz gendiagnostischer Verfahren

\section{INDIKATOR: ENTWICKLUNG DER EINTRÄGE IN DER DNA-ANALYSE-DATEI DES BKA}

\section{DATENQUELLE:}

E-Mail-Anfrage beim BKA.

Auszugsweise Veröffentlichung der Statistik zur DNA-Analyse-Datei. Unter:

http://www.bka.de/nn_205980/DE/ThemenABisZ/DnaAnalyse/Statistik/dnaStatistik__node.html?_nnn=true

Zugriff: September 2014, Stand: Juni/August 2014

\section{VERFÜGBARKEIT DER DATEN:}

öffentlich

Die DNA-Analyse-Datei wird vom Bundeskriminalamt (BKA) seit 1998 geführt und enthält einen Bestand von derzeit etwa 1.081.350 Datensätzen. Diese Zahl setzt sich aus 825.089 Personendatensätzen und 256.261 Spurendatensätzen zusammen (Stand: 31.08.2014). Statistiken zur Datei werden quartalsweise auf der Website des Bundeskriminalamtes veröffentlicht. Ziel der DNA-Datenbank ist die Identifikation von Spurenverursachern an Tatorten. Mithilfe eines DNAAbgleichs können Tatzusammenhänge erkannt, Tatverdächtige überführt und Unschuldige entlastet werden. In der Datei werden sogenannte DNA-Identifizierungsmuster sowie das Geschlecht des Spurenverursachers gespeichert. Die ausschließliche Nutzung von Abschnitten aus den nicht-codierten Bereichen stellt sicher, dass keine Informationen über die Eigenschaften, die Persönlichkeit oder das Aussehen des Spurenverursachers erhoben werden. Mit Hilfe der Datei kann inzwischen jede dritte Spur dem entsprechenden Spurenleger zugeordnet werde (http://www.bka.de/DE/ ThemenABisZ/DnaAnalyse/dnaAnalyse__node.html [22.09.2014]).

\section{ABGRENZUNG DER BERECHNUNGSGRÖSSEN:}

Für die Recherche wurde eine E-Mail-Anfrage über die Website des Bundeskriminalamts gestellt, um eine rückwirkende Auflistung der Spurendatensätze, Personendatensätze, Spur-Spur- und Spur-Personen-Treffer seit 2001, dem Beginn des Gentechnologieberichts, zu generieren. Die Website des BKA veröffentlicht entsprechende Statistiken ausschließlich auszugsweise pro Quartal.

\section{GLIEDERUNG DER DARSTELLUNG:}

a) Entwicklung der Einträge der DNA-Analyse-Datei des BKA

b) Entwicklung der Trefferrate mit Hilfe der DNA-Analyse-Datei des BKA

\section{BERECHNUNGSHÄUFIGKEIT:}

jährlich

\section{AUSSAGEFÄHIGKEIT:}

Der Indikator dokumentiert die Entwicklung der Datensätze in der DNA-Analyse-Datei des BKA respektive der SpurSpur- und Spur-Personen-Treffer, die mit Hilfe dieser Datenbank erzielt werden. Die Entwicklung der Anzahl der Einträge sowie die assoziierte Trefferanzahl geben Aufschluss über die Diffusion wissenschaftlicher Erkenntnisse in den anwendungsbezogenen Bereich. 
a) Abbildung 7: Entwicklung der Einträge der DNA-Analyse-Datei des BKA

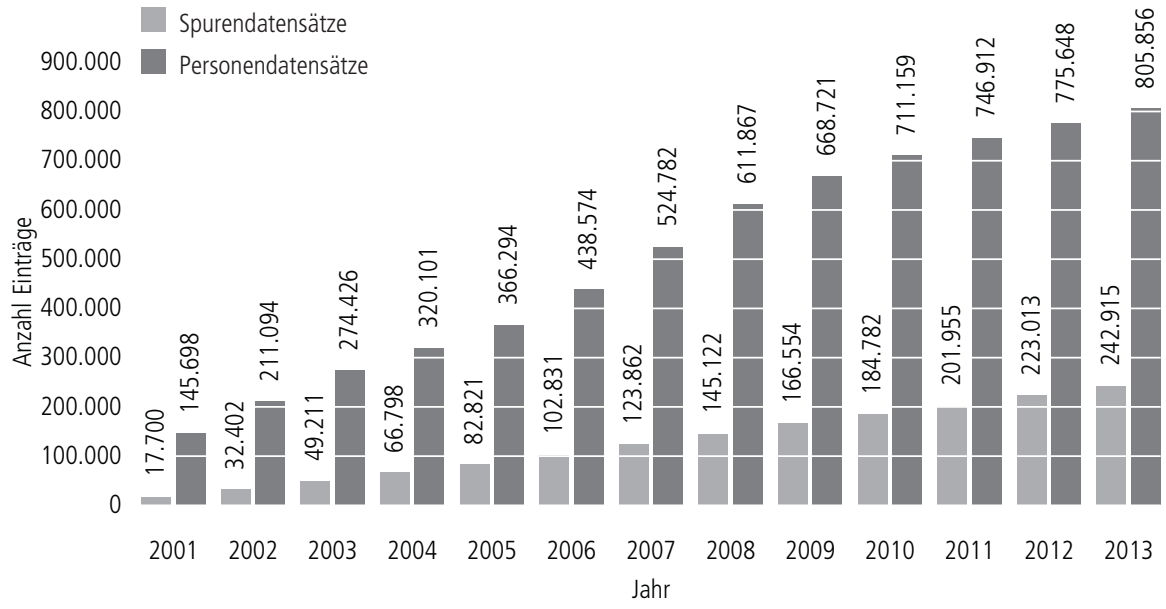

Die Datei wird vom BKA seit 1998 geführt, die Darstellung hier erfolgt ab 2001 dem Beginn des Gentechnologieberichts. Seit 1998 wurden etwa 323.000 Datensätze aufgrund von Fristabläufen oder anderen Gründen wieder gelöscht. Spuren- und Personendatensätze beschreiben genetisches Material, das an Tatorten bzw. von Verdachtspersonen sichergestellt und in die Datei aufgenommen wurde.

Quelle: siehe Indikatorenblatt GD-13. 
b) Abbildung 8: Entwicklung der Trefferrate mit Hilfe der DNA-Analyse-Datei des BKA

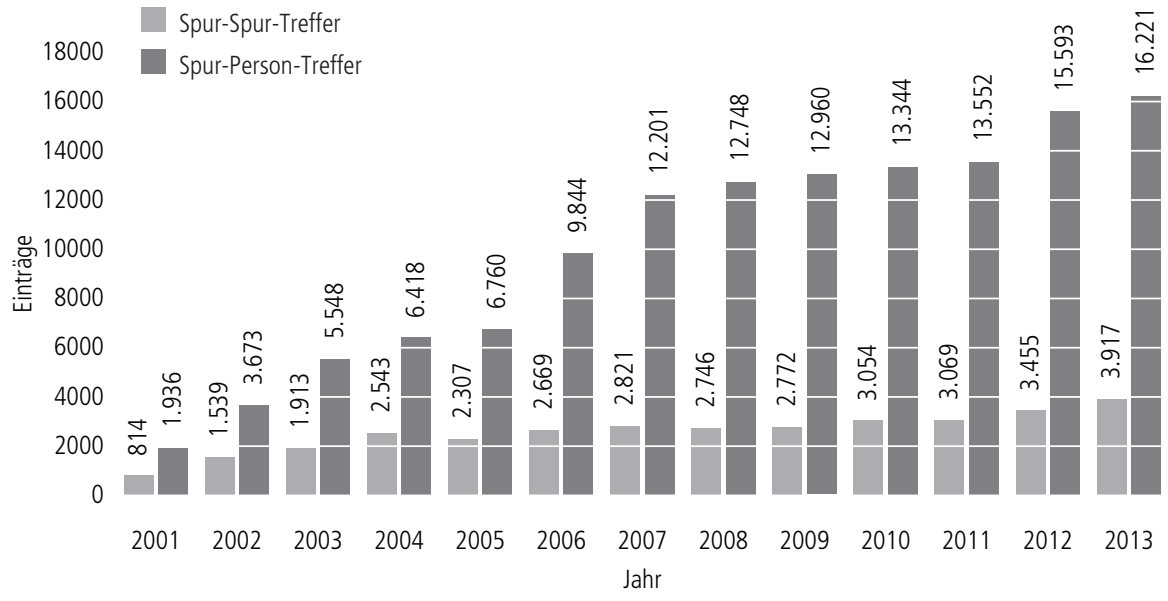

Die Datei wird vom BKA seit 1998 geführt, die Darstellung hier erfolgt ab 2001 dem Beginn des Gentechnologieberichts. Seit 1998 wurden etwa 323.000 Datensätze aufgrund von Fristabläufen oder anderen Gründen wieder gelöscht. Spur-Spur-Treffer geben Aufschluss darüber zwischen welchen Delikten ein Tatzusammenhang besteht, da derselbe Spurenverursacher an verschiedenen Tatorten genetisches Material hinterlassen hat (N seit $1998=35.702$ ). SpurPersonen-Treffer zeigen an, welche Tatortspuren einem Spurenverursacher zugeordnet werden konnten (N seit $1998=$ 139.176). Die Daten lassen nur eine bedingte Aussage zur Aufklärungsrate zu, da die Anwesenheit einer Person und die Hinterlassung genetischen Materials an einem Tatort nicht bedeuten muss, dass die jeweilige Person das Verbrechen auch begangen hat.

Quelle: siehe Indikatorenblatt GD-13. 
Laufende Nr.: GD-14

Problemfeld: Qualitätssicherung/Arztvorbehalt + Angebotsstrukturen

\section{INDIKATOR: ENTWICKLUNG DER FACHÄRZTLICHEN VERSORGUNG IM BEREICH DER HUMANGENETIK IN DEUTSCHLAND}

\section{DATENQUELLE:}

Ärztestatistik der Bundesärztekammer (BÄK)

www.bundesaerztekammer.de

Zugriff: September 2014, Stand: Dezember 2013

\section{VERFÜGBARKEIT DER DATEN:}

\section{öffentlich}

Die BÄK als Arbeitsgemeinschaft der 17 Deutschen Ärztekammern bezeichnet sich selbst als "die Spitzenorganisation der ärztlichen Selbstverwaltung". Sie veröffentlicht jährlich Kennzahlen zum aktuellem Stand und der Struktur der Ärzteschaft in Deutschland. Die Jahresberichte sind auf der Website der BÄK kostenlos einsehbar.

\section{ABGRENZUNG DER BERECHNUNGSGRÖSSEN:}

Es wurde die Anzahl berufstätiger Ärztinnen und Ärzte sowie die Anzahl der erteilten Neuzulassungen für den Bereich Humangenetik aus der Statistik übernommen.

\section{GLIEDERUNG DER DARSTELLUNG:}

Berufstätige Fachärztinnen und -ärzte in Deutschland

\section{BERECHNUNGSHÄUFIGKEIT:}

jährlich

\section{AUSSAGEFÄHIGKEIT:}

Der Indikator dokumentiert die Dichte fachärztlicher Versorgung im Bereich der Humangenetik in Deutschland.

Abbildung 9: Fachärztliche Versorgung im Bereich der Humangenetik in Deutschland

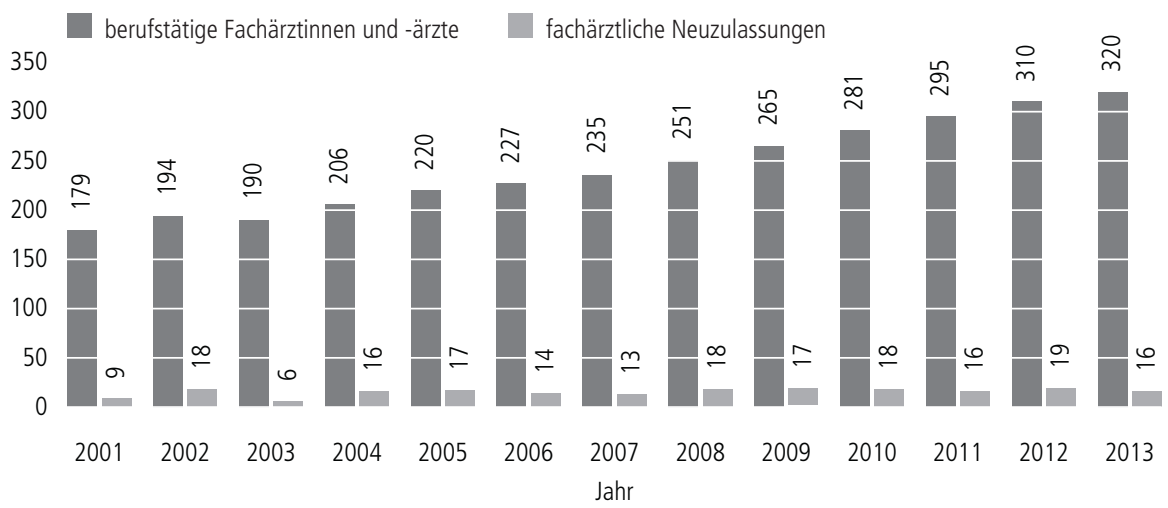


Laufende Nr.: GD-15

Problemfeld: Öffentliche Wahrnehmung

\section{INDIKATOR: PRINTMEDIALE ABBILDUNG DES THEMENBEREICHS GENDIAGNOSTIK}

\section{DATENQUELLE:}

Frankfurter Allgemeine Zeitung. Unter: www.faz.net

Süddeutsche Zeitung. Unter: www.sueddeutsche.de

Die Zeit. Unter: www.zeit.de

Der Spiegel. Unter: www.spiegel.de

Zugriff (alle): August 2014, Stand: August 2014

\section{VERFÜGBARKEIT DER DATEN:}

mehrheitlich öffentlich

Die Recherche in den Online-Archiven der ausgewählten deutschen Zeitungen und Zeitschriften ist mit Ausnahme der Süddeutschen Zeitung (SZ) kostenlos zugänglich. Beiträge zu ausgewählten Suchbegriffen können hier tagesaktuell recherchiert werden, jedoch können die Presseartikel der Frankfurter Allgemeinen Zeitung (F.A.Z.) mehrheitlich nur kostenpflichtig abgerufen werden.

\section{ABGRENZUNG DER BERECHNUNGSGRÖSSEN:}

Für die Recherche relevanter Printartikel wurde das Stichwort "Gendiagnostik" im Volltext ab 2001 (Beginn der IAG Gentechnologiebericht) überregional gesucht. Ausschließlich online erschienene Presseartikel, Artikel in Sonderheften sowie regionale und in anderen Medien erschienene Beiträge wurden dabei nicht berücksichtigt. Es wurde keine weiterführende qualitative Filterung der Suchergebnisse vorgenommen.

\section{GLIEDERUNG DER DARSTELLUNG:}

Anzahl an Printartikeln zum Stichwort "Gendiagnostik"

\section{BERECHNUNGSHÄUFIGKEIT:}

jährlich

\section{AUSSAGEFÄHIGKEIT:}

Der Indikator dokumentiert die Dichte der öffentlichen Berichterstattung zum Themenbereich im dargestellen Zeitraum in ausgewählten überregionalen Printmedien. Diese erreichen - das dokumentieren die Auflagezahlen - eine Vielzahl an Menschen in ganz Deutschland, die sich auf diesem Weg über den Themenbereich informieren können. 
Abbildung 10: Anzahl an Printartikeln zum Stichwort "Gendiagnostik"

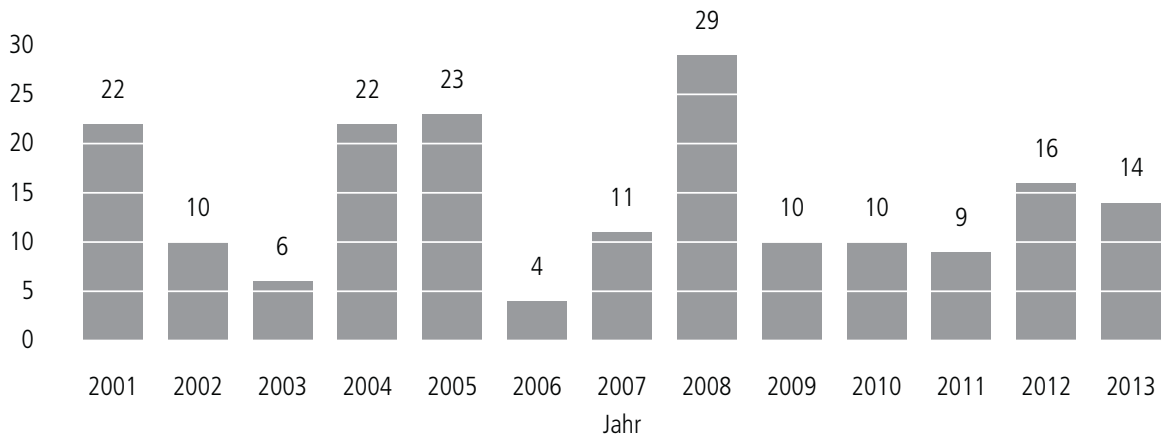

Quelle: siehe Indikatorenblatt GD-15. 
Laufende Nr.: GD-16

Problemfeld: Öffentliche Wahrnehmung

\section{INDIKATOR: NEUERSCHEINUNGEN ZUM THEMENBEREICH GENDIAGNOSTIK}

\section{DATENQUELLE:}

Online-Katalog der Deutschen Nationalbibliothek. Unter: https://portal.dnb.de

Zugriff: August 2014, Stand: k. A.

\section{VERFÜGBARKEIT DER DATEN:}

öffentlich

Die Nationalbibliothek (DNB) ist eine bundesunmittelbare Anstalt des öffentlichen Rechts. Ihre Aufgabe ist die Archivierung und bibliografische Erfassung in Deutschland veröffentlichter Medienwerke (Monografien, Zeitungen, Zeitschriften, Loseblattwerke, Karten, Musikalien, Tonträger, elektrische Publikationen). Darüber hinaus werden auch im Ausland veröffentlichte deutschsprachige Medienwerke, im Ausland veröffentlichte Übersetzungen deutschsprachiger Medienwerke, fremdsprachige Medienwerke über Deutschland sowie Exilpublikationen deutschsprachiger Emigranten zwischen 1933 und 1950 erfasst. Seit 2006 werden zusätzlich Online-Publikationen systematisch berücksichtigt. Der Katalog der Deutschen Nationalbibliothek erlaubt eine kostenlose Recherche innerhalb der umfassenden Bibliotheksbestände seit 1913. Nach Anbieterangaben werden eingegangene Publikationen mit einer Bearbeitungszeit von ca. einem Monat in den Katalog und in die Deutsche Nationalbibliografie eingetragen.

\section{ABGRENZUNG DER BERECHNUNGSGRÖSSEN:}

Für die Recherche relevanter Titel wurde der Suchbegriff "Gendiagnostik” im Modus „Expertensuche" im gesamten Bestand des Katalogs der Deutschen Nationalbibliolthek ab 2001 (Beginn des Gentechnologieberichts) gesucht. Da es sich um eine Suche nach einem speziellen Begriff handelt, wurde über die Titelfelder hinausgehende Suchfunktion (Index=woe) verwendet. Im Bestand vermerkte Hochschulschriften wurden explizit ausgenomen, da sie für den interessierten Laien schwer zugänglich sind. Generell ausgeschlossen wurden Periodika sowie Normdaten für einzelne Personen, Organisationen, Veranstaltungen, Geografika, Sachbegriffe und Werktitel, die im Katalog der DNB geführt werden. Es wurde keine weiterführende qualitative Filterung der Suchergebnisse vorgenommen.

GLIEDERUNG DER DARSTELLUNG:

Anzahl an Neuerscheinungen zum Stichwort "Gendiagnostik"

BERECHNUNGSHÄUFIGKEIT:

jährlich

\section{AUSSAGEFÄHIGKEIT:}

Der Indikator dokumentiert die publizistische Dichte für den Themenbereich. Er zählt diejenigen Materialien, die auch der interessierten Öffentlichkeit frei zur Verfügung stehen. Über die (etwa in Fachjournalen geführte) wissenschaftsinterne Aushandlung liefert er keine Aussage. 
Abbildung 11: Anzahl an Neuerscheinungen zum Stichwort "Gendiagnostik"

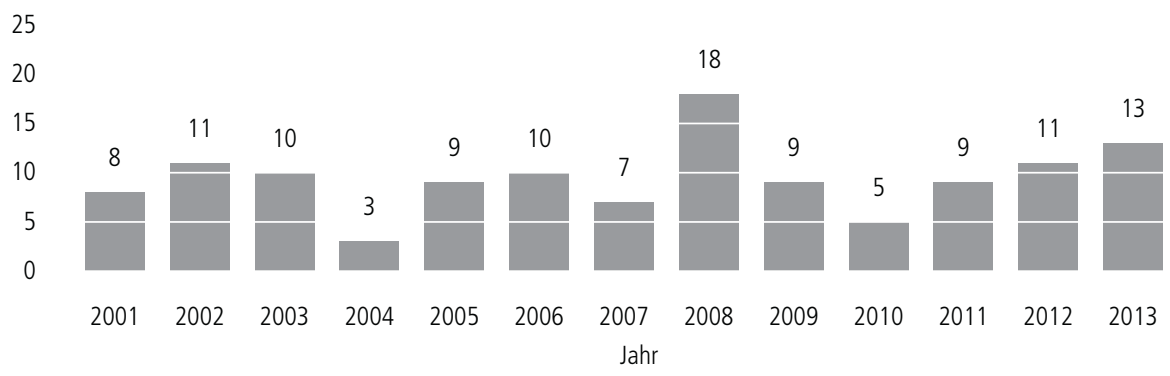

Erfassung der im DNB-Katalog verzeichneten Titel bis zum Stichtag am 06.08.2014. Erweiterter Recherchemodus; Unterschiede zu früheren Veröffentlichungen möglich.

Quelle: siehe Indikatorenblatt GD-16. 
Laufende Nr.: GD-17

Problemfeld: Öffentliche Wahrnehmung

\section{INDIKATOR: INTERNETPRÄSENZ ZUM THEMA GENDIAGNOSTIK}

\section{DATENQUELLE:}

Google - Suchmaschine. Unter: www.google.de

Zugriff: Oktober 2014, Stand: $k$. A.

\section{VERFÜGBARKEIT DER DATEN:}

öffentlich

\section{ABGRENZUNG DER BERECHNUNGSGRÖSSEN:}

Für die Recherche wurde das Stichwort "Gendiagnostik" mit der Suchmaschine Google gesucht; diese Suchmaschine stellt das am häufigsten in Deutschland genutzte Portal für die Online-Recherche dar. Es werden monatlich die Anzahl an gefundenen Webseiten gemittelt; es erfolgt keine weiterführende qualitative Auswertung der Suchergebnisse. Die Datenerhebung erfolgt seit April 2011. Es muss darauf hingewiesen werden, dass der Internetauftritt der Suchmaschine ständig weiterentwickelt wird und dadurch bedingte Abweichungen zwischen den einzelnen Monaten möglich sind.

\section{GLIEDERUNG DER DARSTELLUNG:}

Trefferanzahl bei der Stichwortsuche unter Google

\section{BERECHNUNGSHÄUFIGKEIT:}

monatlich

\section{AUSSAGEFÄHIGKEIT:}

Der Indikator dokumentiert die öffentliche Präsenz und zugleich Auseinandersetzung mit dem Thema Gendiagnostik anhand von verfügbaren Webseiten im Internet. Die interessierte Öffentlichkeit kann sich auf diesem Weg weiterführend über das Forschungsfeld informieren. Es ist allerdings möglich, dass die von der Suchmaschine vorgeschlagenen Webseiten sich nicht ausschließlich mit relevanter Forschung befassen, sondern dass Gendiagnostik nur als randständiges Thema auftritt. Außerdem ist die Qualität der online präsentierten Informationen nicht unmittelbar einschätzbar.

Abbildung 12: Trefferanzahl bei der Stichwortsuche unter Google

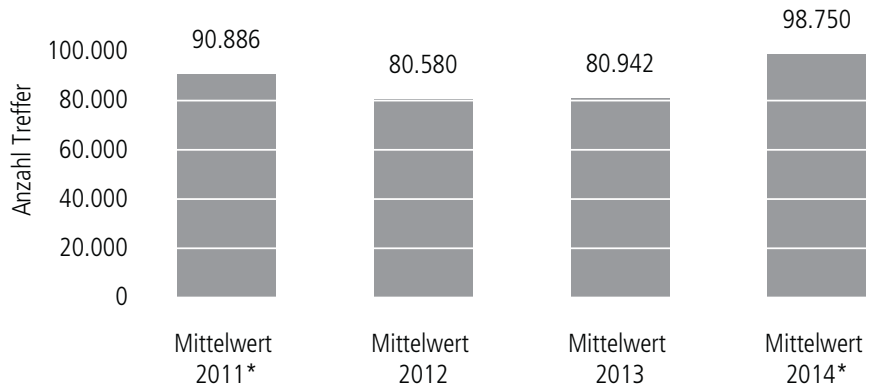

*Daten ab April 2014 bzw. bis Oktober 2014

Quelle: siehe Indikatorenblatt GD-17. 


\subsubsection{Zusammenfassung}

Es ergibt sich in der Gesamtschau folgendes Bild für den Themenbereich Gendiagnostik:

- Das Forschungsfeld der Gendiagnostik ist offensichtlich von technischen Weiterentwicklungen geprägt. Das hierdurch entstehende Mehrwissen über genetische Krankheiten schlägt sich allerdings nicht, wie die Zahlen zeigen, zwangsläufig in einem Anstieg der Gentests anbietenden Labore nieder (GD-01).

- Die 1997 gegründete European Society of Human Reproduction and Embryology (ESHRE) sammelt seit 1999 europaweite Daten zu durchgeführten präimplantationsdiagnostischen Verfahren. Für den dritten Bericht wurden diejenigen Verfahren in Augenschein genommen, die bis Dezember 2008 durchgeführt wurden. Das aktuell verfügbare Zahlenmaterial wurde entsprechend aufgearbeitet und zeigt eine stabile Tendenz seit dem Erscheinen des letzten Berichts. Aufgrund des Erhebungszeitraums bildet die Tabelle noch nicht die begrenzte Zulassung der PID in Deutschland seit $2014 \mathrm{ab}$ (GD-03).

- Während der zweiten Berichtsphase (2005-2009) zeigte sich noch ein sprunghafter Anstieg an veröffentlichten genomweiten Assoziationsstudien, diese pegelten sich jetzt in der dritten Berichtsphase (2010-2013) bei rund 370 pro Jahr ein, zuletzt mit sinkender Tendenz (GD-07).

- Die Akkreditierung von medizinischen Laboren ist einem Zentralisierungsprozess unterworfen. Die hier aufgebotenen Daten sind daher nur bedingt anschlussfähig an die vorangegangene Berichterstattung. Explizite Tendenzen werden sich erst zukünftig abzeichnen (GD-10). Der Qualitätssicherung dienen ebenfalls Ringversuche, ihre Anzahl ist (bezogen auf abgeschlossene Versuche) auch im dritten Berichtszeitraum weiter gestiegen (GD-11).

- Die Einträge der DNA-Analyse-Datei des Bundeskriminalamtes haben sich seit 2001 mehr als versechsfacht und zeigen somit, wie stark hier DNA-Analysemethoden in den Anwendungsbereich diffundiert sind (GD-13).

- Die Anzahl an berufstätigen Fachärztinnen und -ärzten für die Humangenetik ist in den beiden letzten Berichtszeiträumen stetig gestiegen. Diese Entwicklung lässt sich als Indiz eines sich prosperierenden Feldes deuten. 2013 erging eine Zulassungssperre durch die Bundesärztekammer. Ein Trend wird sich entsprechend erst in den kommenden Jahren ablesen lassen (GD-14).

- Ein konstantes mediales Interesse ist im Berichtszeitraum erkennbar. Durch die Popularität einzelner Verfahren jedoch, wie zum Bespiel der PID, differenziert sich das Feld aus, so dass sich entsprechende Berichterstattung nicht mehr unter dem Label "Gendiagnostik“ auffinden lässt (GD-15). 
- Die Zahl an neu erschienenen Büchern zum Thema ist im Berichtszeitraum jährlich gestiegen, insgesamt erschienen hier 28 entsprechende Publikationen. Hier lässt sich ein Interesse auch jenseits des primär in Fachzeitschriften geführten naturwissenschaftlichen Fachdiskurses ausmachen, das der interessierten Öffentlichkeit auch in deutscher Sprache zur Verfügung steht (GD-16).

- Die öffentlichkeitswirksame Auseinandersetzung mit der Gendiagnostik spiegelt sich auch in der über den Beobachtungszeitraum hohen Trefferzahl in der InternetSuchmaschine Google wider (GD-17).

\subsection{Literatur}

Annas, G. J./Elias, S. (2014): 23andMe and the FDA. In: N Engl J Med 370(11):9858.

Bainbridge, M. N. et al. (2013): De novo truncating mutations in ASXL3 are associated with a novel clinical phenotype with similarities to Borhing-Opitz syndrome. In: Genome Med 5:11.

BBAW = Berlin Brandenburgische Akademie der Wissenschaften (2013): Stellungnahme zu den neuen Sequenzierungstechniken und ihren Konsequenzen für die genetische Krankenversorgung. Berlin.

Beaulieu, C. L. et al. (2014): FORGE Canada Consortium: Outcomes of a 2-Year National Rare-Disease Gene-Discovery Project. In: Am J Hum Genet 94: 809817.

Bell, C. J. et al. (2011): Carrier testing for severe childhood recessive diseases by next-generation sequencing. In: Sci Transl Med 3(65):65ra4.

Check Hayden, E. (2009): Genomics shifts focus to rare diseases. In: Nature 461(7263):458

Cooper, D. N. et al. (2010): Genes, mutations, and human inherited disease at the dawn of the age of personalized genomics. In: Hum Mutat 31(6):631-55.

De Ligt, J. et al. (2012): Diagnostic exome sequencing in persons with severe intellectual disability. In: N. Engl. J. Med. 367(20):1921-1929.

Deutscher Ethikrat (Hrsg.) (2013): Die Zukunft der genetischen Diagnostik - von der Forschung in die klinische Anwendung. Stellungnahme. Berlin:110.

Dewey, F. E. et al. (2014): Clinical Interpretation and Implications of Whole-Genome Sequencing. In: JAMA 311(10):103545.

Gilissen, C. et al. (2014): Genome sequencing identifies major causes of severe intellectual disability. In: Nature, Online-Publikation 05.06.2014. Doi:10.1038/nature13394.

Gonzales-Garay, M. L. et al. (2013): Personalized genomic disease risk of volunteers. In: Proc Natl Acad Sci U S A 110(42):16957-16962.

Green, R. C. et al (2013): ACMG recommendations for reporting of incidental findings in clinical exome and genome sequencing. In: Genet Med 15:565574. 
Heger, M. (2014): Emory Launches Medical Exome with Enhanced Coverage of Disease-Associated Genes. In: Genome Web,19.03.2014.

Hucho, F. et al. (2005): Gentechnologiebericht. Analyse einer Hochtechnologie in Deutschland. München.

Hutchinson, C. A. (2007): DNA sequencing: bench to bedside and beyond. In: Nucl Acid Res 35:62276237.

Iglesias, A. et al. (2014): The usefulness of whole-exome sequencing in routine clinical practice. In: Genetics in Medicine, Online-Publikation 05.06.2014. Doi:10.10.1038/gim.2014.58.

Krüger-Brand, H. E. (2009) Gesundheitsinformationen im Internet. In: Dtsch Arztebl 106(50) Suppl PRAXis 2009/5:3.

Landers, N. J. et al. (2001): Initial sequencing and analysis of the human genome. In: Nature 409(6822):860-921.

Lohman, N. J. et al. (2012): Performance comparison of benchtop high-throughput sequencing platforms. In: Nat Biotechnol 30(5):434-9.

Lynch, H. T. (2010): Rate, molecular spectrum, and consequences of human mutation. In: Proc Natl Acad Sci USA 107(3):961-8.

Margulies, M. et al. (2005): Genome sequencing in microfabricated high-density picolitre reactors. In: Nature 437:376-380.

Müller-Röber, B. et al. (2009): Zweiter Gentechnologiebericht. Analyse einer Hochtechnologie in Deutschland. Dornburg.

Najmabadi, H. et al. (2011): Deep sequencing reveals 50 novel genes for recessive cognitive disorders. In: Nature 478(7367):57-63.

Rauch, A. et al. (2012): Range of genetic mutations associated with severe non-syndromic sporadic intellectual disability: an exome sequencing study. In: Lancet 380(9854):1674-1682.

Ropers, H. H./ Ullmann, R. (2007): Neue Technologien für Genomforschung und Diagnostik. In: Schmidtke et.al.: Gendiagnostik in Deutschland. Limburg an der Lahn.

Ropers, H. H. (2010): Single gene disorders come into focus - again. In: Dialogues Clin Neurosci 12(1):95-102.

Ropers, H. H. (2012 a): On the future of genetic risk assessment. In: J Community Genet 3(3):229-36.

Ropers, H.H. (2012 b): Ropers: Je moet niet bang zijn voor je eigen genoom. In: NRC Handelsblad, October 2012.

Ropers, H.H. (2013 ): Wer hat Deutungshoheit über das menschliche Genom? In: F.A.Z, 22.11.2013.

Rothberg, J. M. /Leamon, J. H. (2008): The development and impact of 454 sequencing. In: Nat Biotechnol 26(10):1117-24.

Sanger F. et al. (1977): DNA sequencing with chain-terminating inhibitors. In: Proc Nat Acad Sci USA 74:5463-5467. 
Schadt, E. E. et al. (2010): A window into third-generation sequencing.

Schmidtke, J. et al. (Hrsg.) (2007): Gendiagnostik in Deutschland. Status quo und Problemerkundung. Limburg an der Lahn.

Schmidtke, J./Cassiman, J.-J. (2010): The EuroGentest clinical utility gene cards. In: Eur J Hum Gen 18(9).

Thompson, J. F. /Milos, P. M. (2011): The properties and applications of single-molecule DNA sequencing. In: Genome Biology 12:217.

Umbarger, M. A. et al. (2014): Next-generation carrier screening. In: Genetics in Medicine 16:132140.

van Zelst-Stams, W. A. et al. (2014): Clinical exome sequencing in daily practice: 1,000 patients and beyond. In: Genome Medicine 6:2.

Venter, J. C. et al. (2001): The sequence of the human genome. In: Science 291(5507):1304-1351.

Yang, Y. et al. (2013): Clinical whole-exome sequencing for the diagnosis of mendelian disorders. In: N Engl J Med 369:1502-1511.

Zielinksi, D. et al. (2012): Back to the family: a renewed approach to rare variant studies. In: Genome Med 4(12):97

Zuk, O. et al. (2012): The mystery of missing heritability. Genetic interactions create phantom heritability. Proc Natl Acad Sci USA 109(4):1193-8. 
